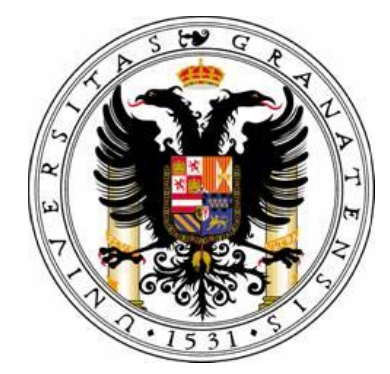

Universidad de Granada

Escuela Internacional de Posgrado

Máster en Didáctica de la Matemática

\title{
SIGNIFICADOS ESCOLARES DEL CONCEPTO DE PORCENTAJE
}

\author{
Trabajo Fin de Máster
}

Mery Salinas Hernández

Granada, 2016 


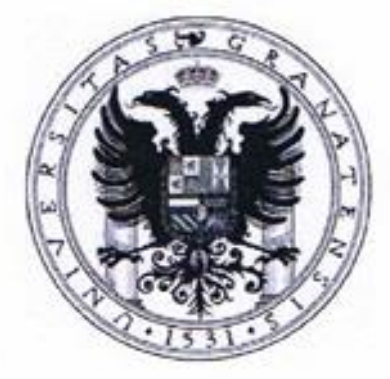

Universidad de Granada

Escuela Internacional de Posgrado

Máster en Didáctica de la Matemática

\section{SIGNIFICADOS ESCOLARES DEL CONCEPTO DE PORCENTAJE}

Trabajo fin de máster realizado bajo la dirección del Doctor Luis Rico Romero y la Doctora Elena Castro Rodríguez de la Universidad de Granada que presenta Mery Salinas Hernández para su aprobación en el Programa de Máster en Didáctica de la Matemática de la Universidad de Granada.

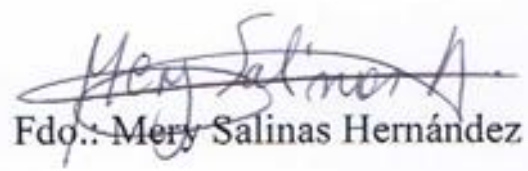

$\mathrm{V}^{\circ} \mathrm{B}^{\circ}$ del director

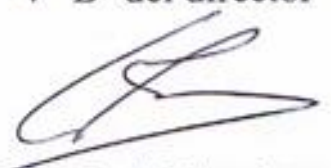

Fdo.. Dr. Luis Rico Romero
$\mathrm{V}^{\circ} \mathrm{B}^{\circ}$ de la codirectora

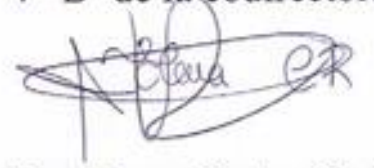

Fdo.: Dra. Elena Castro Rodríguez 
Este trabajo se ha realizado en el Grupo de Investigación FQM-193 del Plan Andaluz de Investigación, Desarrollo e Innovación de la Junta de Andalucía "Didáctica de la Matemática: Pensamiento Numérico" de la Universidad de Granada, y con el apoyo del Proyecto «Conocimiento Didáctico del Profesor y Aprendizaje de Conceptos Matemáticos Escolares» (EDU2015-70565-P) del Plan Nacional de I+D+I (MICIN). 
A mi familia:

Mi madre, por todo su amor y entrega

Mi padre, por su ejemplo de esfuerzo y perseverancia

Mi tata Luis, por su cariño Y a la memoria de mi abuela María 


\section{Agradecimientos}

En primer lugar, agradezco al profesor Luis Rico Romero su apoyo, su orientación constante, todas sus enseñanzas y paciencia al dirigir este trabajo. De la misma manera, agradezco la dedicación de la profesora Elena Castro Rodríguez, su buena disposición y valiosas aportaciones.

Muchas gracias al profesorado del Master en Didáctica de la Matemática de la Universidad de Granada, por compartir sus saberes y experiencias, especialmente aquellos con quienes estuve en clases.

Gracias a la Comisión Nacional de Investigación Científica y Tecnológica del Gobierno de Chile (CONICYT), que mediante su Programa de Capital Humano Avanzado me han otorgado la Beca para cursar los estudios de este máster.

Infinitas gracias a todas las personas que han hecho posible la culminación de este trabajo, a quienes generosamente han aportado sus conocimientos y experiencias, su disposición por colaborar, sus consejos, su tiempo, su cariño y compañía. De aquí o de allá, amigos, compañeros y colegas, mi gratitud por el apoyo brindado.

Muchas gracias a los centros educativos que participaron del estudio, el profesorado que cedió tiempo de sus clases, el alumnado que proporcionó sus respuestas y a los encuestadores que gentilmente colaboraron en la recogida de datos.

Gracias a mi familia por hacerme sentir su amor incondicional pese a la distancia, su motivación a dar lo mejor y cumplir las metas propuestas.

Finamente, doy gracias a mi Dios, quien cada día me ha dado la fuerza para enfrentar este desafío y me ha acompañado en todo momento. 


\section{ÍNDICE}

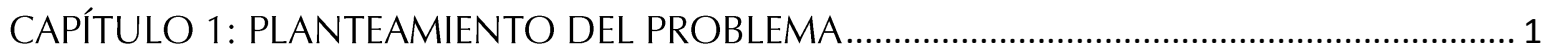

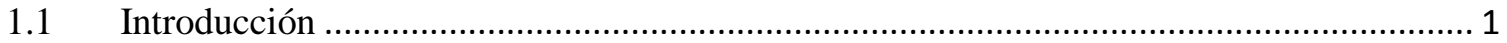

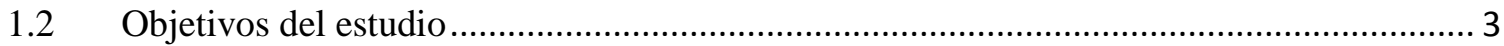

CAPÍTULO 2: FUNDAMENTACIÓN TEÓRICA.................................................................... 5

2.1 Antecedentes de investigaciones sobre el porcentaje .................................................... 5

2.2 Los contenidos sobre porcentaje en el currículo chileno................................................ 7

2.3 Significado de un concepto matemático escolar ................................................................. 8

$2.4 \quad$ Análisis de contenido del concepto de porcentaje......................................................... 10

2.4.1 Sentidos y modos de uso del porcentaje...................................................................... 11

2.4.2 Sistemas de representación del porcentaje .................................................................. 15

2.4.3 Estructura conceptual del porcentaje......................................................................... 18

CAPÍTULO 3: MARCO METODOLÓGICO …..................................................................... 23

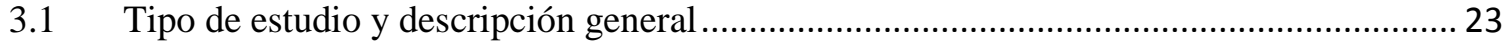

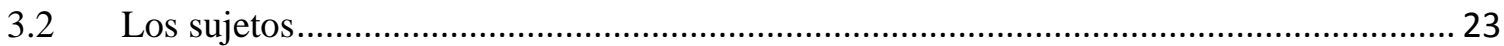

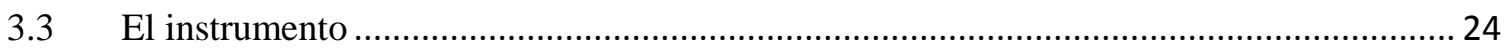

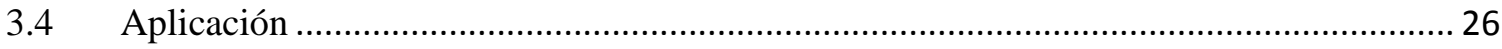

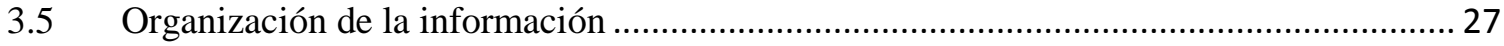

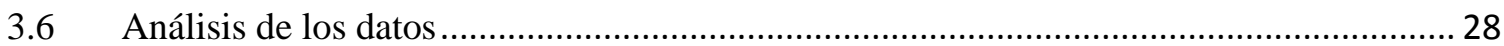

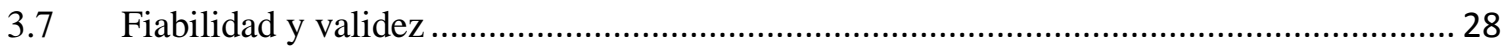

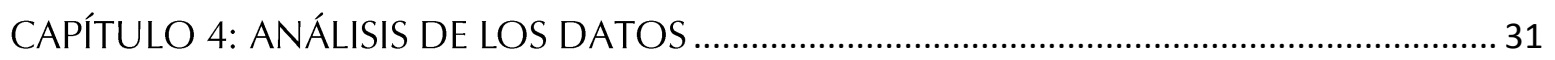

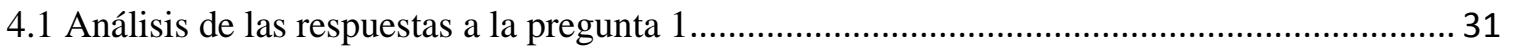

4.1.1 Análisis a la pregunta 1 desde las componentes de la terna semántica .......................... 38

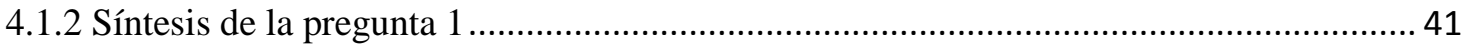

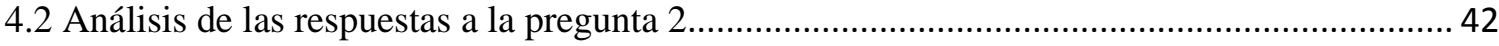

4.2.1 Análisis a la pregunta 2 desde las componentes de la terna semántica ............................52

4.2.2 Síntesis de los resultados a la pregunta 2 .................................................................. 53

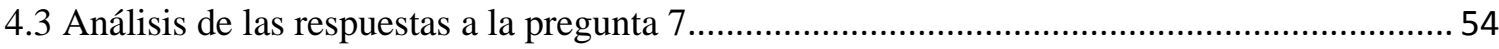

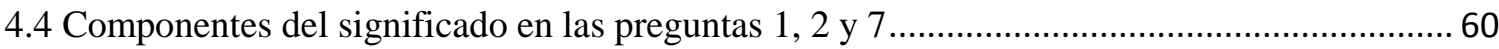

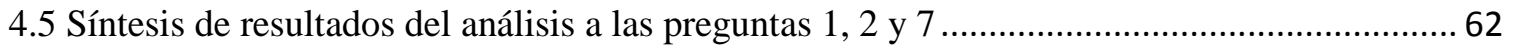




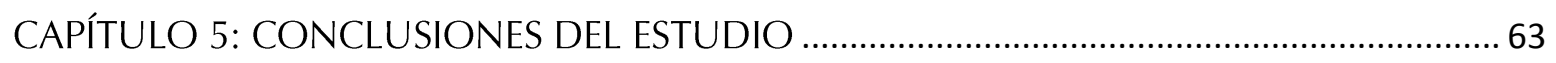

5.1 Conclusiones generales en función de los objetivos planteados ............................................ 63

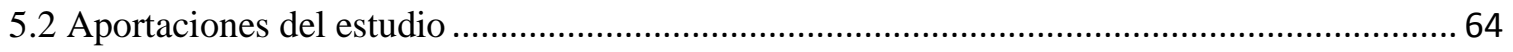

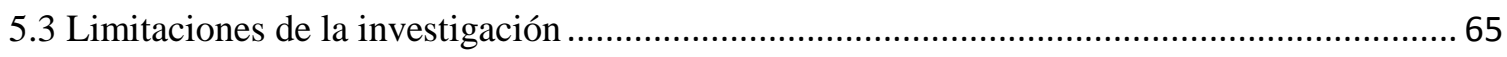

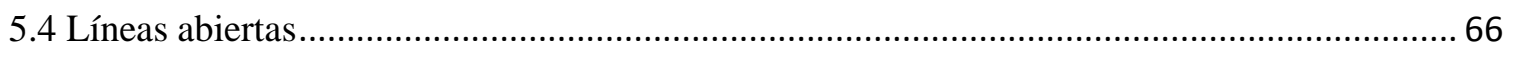

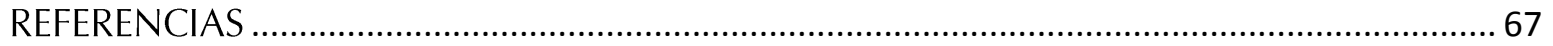

ANEXOS

Anexo A: Antecedentes históricos del porcentaje y de su notación............................................. 72

Anexo B: Normas de escritura de porcentajes ..................................................................... 73

Anexo C: Descripción de los centros participantes del estudio .................................................. 74

Anexo D: Descripción de las fases de elaboración del cuestionario ............................................. 75

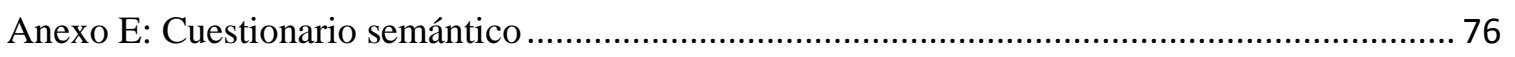

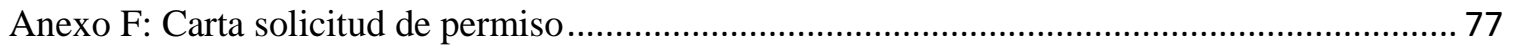

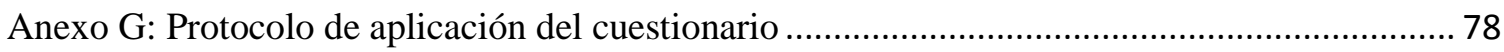

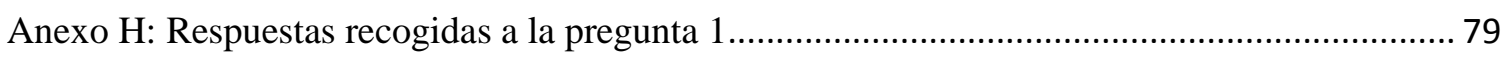

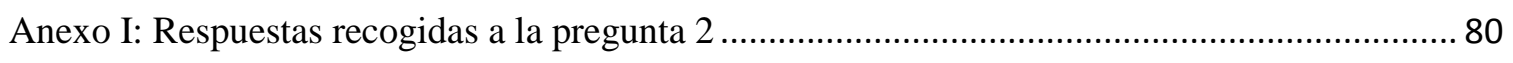

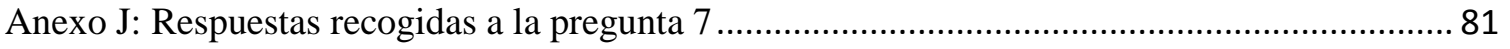




\section{Índice de tablas}

Tabla 1. Notaciones y símbolos para el porcentaje ….................................................................... 17

Tabla 2. Razonamientos sobre el concepto de porcentaje .......................................................... 21

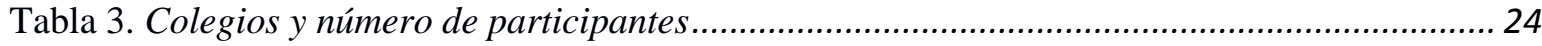

Tabla 4. Respuestas obtenidas en cada pregunta.......................................................................... 31

Tabla 5. Respuestas distintas a la pregunta 1 ............................................................................. 32

Tabla 6. Situaciones personales identificadas en las respuestas a la pregunta 1.......................... 33

Tabla 7. Situaciones educativas o laborales identificadas en las respuestas a la pregunta 1 .......... 34

Tabla 8. Situaciones públicas identificadas en las respuestas a la pregunta 1 .............................. 35

Tabla 9. Situaciones científicas identificadas en las respuestas a la pregunta 1............................ 36

Tabla 10. Otras situaciones identificadas en las respuestas a la pregunta 1 ................................. 36

Tabla 11. Sistemas de representación identificados en la pregunta 1 ............................................. 38

Tabla 12. Elementos de la estructura conceptual identificados en la pregunta 1............................ 40

Tabla 13. Síntesis de resultados a la pregunta 1........................................................................... 41

Tabla 14. Frecuencia de respuestas distintas a la pregunta 2 ..................................................... 42

Tabla 15. Variantes de representación gráfica ............................................................................. 44

Tabla 16. Variantes de representación con gráficas estadísticas ................................................. 45

Tabla 17. Variantes de representación numérico-simbólica........................................................ 47

Tabla 18. Variantes de repuesta con notación fraccionaria ........................................................... 48

Tabla 19. Variantes de representación con notación decimal ...................................................... 48

Tabla 20. Variantes de respuestas con notación de razón .............................................................. 49

Tabla 21. Variantes de representación numérico - verbal ............................................................. 50

Tabla 22. Variantes de respuestas de relaciones aritméticas ........................................................ 51

Tabla 23. Otros modos de representación...................................................................................... 52

Tabla 24. Sintesis de representaciones para el porcentaje ........................................................... 53

Tabla 25. Frecuencia de respuestas distintas a la pregunta 7 ......................................................5

Tabla 26. Tipos de representaciones identificadas en la pregunta 7 ............................................ 55

Tabla 27. Tipos de sentidos y modos de uso identificados en la pregunta 7 ...................................5 57

Tabla 28. Elementos de la estructura conceptual identificados en la pregunta 7 .............................. 59

Tabla 29. Representaciones en las preguntas 1,2 y 7 .................................................................. 61

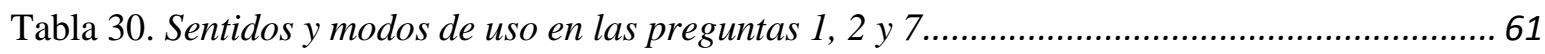

Tabla 31. Estructura conceptual en las preguntas 1, 2 y 7 ....................................................... 61 


\section{Índice de figuras}

Figura 1. Terna semántica de Frege....................................................................................... 8

Figura 2. Terna semántica del significado de un concepto matemático escolar.............................. 9

Figura 3. Representaciones gráficas del porcentaje............................................................... 17

Figura 4. Representación de porcentajes en la recta numérica discreta....................................... 18

Figura 5. Respuesta de C7a20 a la pregunta 1 ....................................................................... 36

Figura 6. Respuesta de B7a05 a la pregunta 1.................................................................... 37

Figura 7. Respuesta de B7a06 a la pregunta 1.................................................................... 37

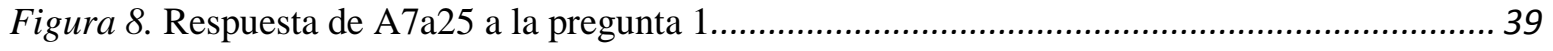

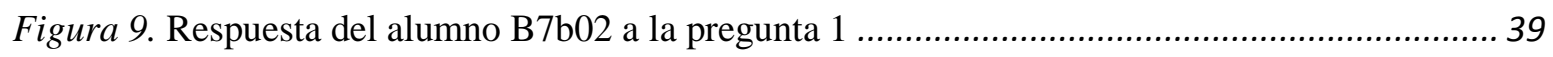

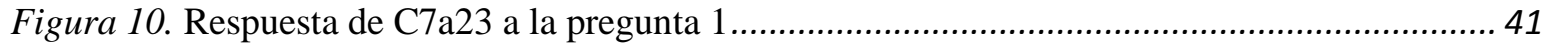

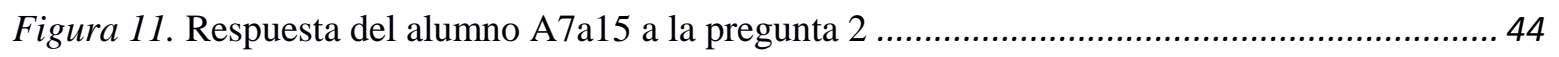

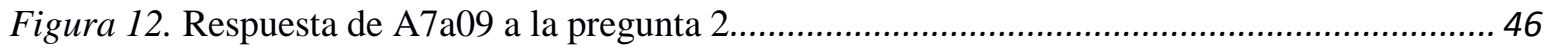

Figura 13. Respuesta de A7a25 a la pregunta 2................................................................... 46

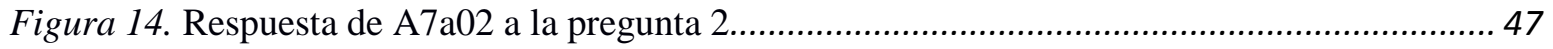

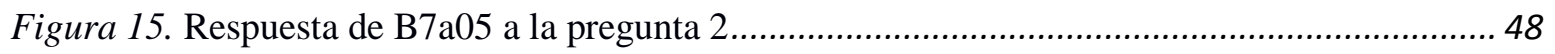

Figura 16. Respuesta de A7a14 a la pregunta 2....................................................................... 49

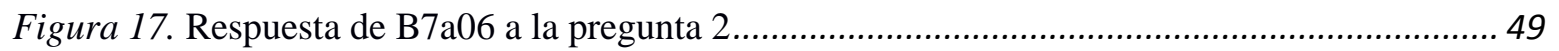

Figura 18. Respuesta de B7a02 a la pregunta 2 .................................................................... 50

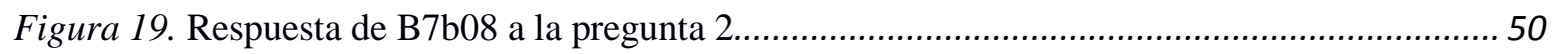

Figura 20. Respuesta de B7a17 a la pregunta 2.................................................................... 51

Figura 21. Respuesta de A7a17 a la pregunta 2................................................................... 52

Figura 22. Respuesta de A7a09 y de B7a15 a la pregunta 2 ................................................... 52

Figura 23. Respuesta de A7a07 a la pregunta 2.................................................................. 53

Figura 24. Respuesta de C7a24 a la pregunta 2................................................................... 53

Figura 25. Respuesta de A7a17 a la pregunta 7..................................................................... 56

Figura 26. Respuesta de C7a36 a la pregunta 7 ......................................................................5 56

Figura 27. Respuesta de B7a08 a la pregunta 7 ................................................................. 56

Figura 28. Respuesta de A7a25 a la pregunta 7.................................................................... 58

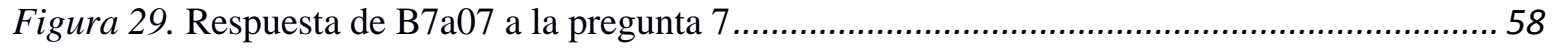

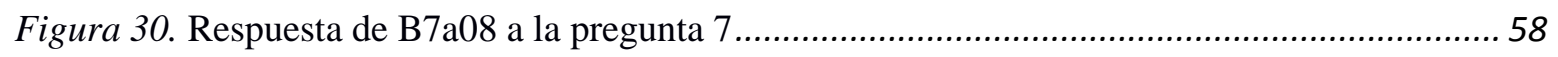

Figura 31. Respuesta de B7a02 a la pregunta 7 ................................................................... 59

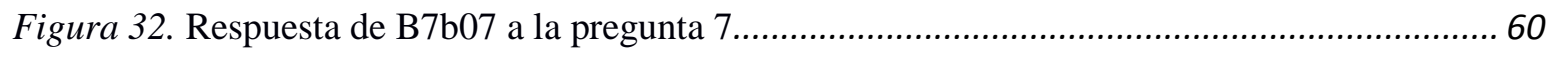




\section{CAPÍTULO 1: PLANTEAMIENTO DEL PROBLEMA}

\subsection{Introducción}

El porcentaje es uno de los conceptos matemáticos con mayor presencia en la vida cotidiana. A menudo recibimos información que incluye porcentajes: en el comercio, las noticias, los periódicos o la televisión, entre otros. Generalmente este concepto se utiliza para comunicar información de manera sencilla y precisa, por ejemplo: "rebajas del 30\% en todos los artículos del hogar" o "el valor del gas licuado aumentó un $5 \%$ el último trimestre".

El National Council of Teachers of Mathematics (NCTM, 2000, pp. 218-220), señala que los estudiantes de los niveles educativos medios deberían "ampliar su repertorio de significados, representaciones y usos de los números naturales, fracciones, decimales y porcentajes. De esta manera, se sugiere profundizar en la comprensión, potenciar el desarrollo de habilidades y destrezas que les permitan resolver problemas cotidianos con ellos, fortalecer el conocimiento de los conceptos y comprender las diferentes formas de representación y sus equivalencias". Además, este documento subraya que los porcentajes proporcionan a los estudiantes otra manera útil de representar los números racionales, combinando aspectos de las fracciones y los decimales. Añade que "son particularmente convenientes para comparar partes fraccionarias de conjuntos o de números de distinto tamaño, lo cual se presenta con frecuencia en problemas de la vida diaria” (p. 221).

Desde los documentos curriculares españoles, se enfatiza la necesidad de formar ciudadanos preparados matemáticamente, competentes para comprender, procesar e interpretar la información que reciben a través de diferentes formas (tablas, gráficas, porcentajes, etc.), de modo que puedan tomar decisiones en su vida cotidiana. Se explicita la necesidad de que el alumnado logre una comprensión de las operaciones que permita razonar sobre las mismas, y establecer relaciones entre las distintas formas de 
representación numérica (fracciones, decimales y porcentajes). De esta forma, en el Real Decreto 126/2014, de 28 de febrero, por el que se establece el currículo básico de la Educación Primaria, se explicita el tratamiento de la noción de porcentaje junto con la proporcionalidad. El enunciado "Resuelve problemas de la vida cotidiana utilizando porcentajes y regla de tres en situaciones de proporcionalidad directa, explicando oralmente y por escrito el significado de los datos, la situación planteada, el proceso seguido y las soluciones obtenidas", se plantea como estándar de aprendizaje evaluable (Ministerio de Educación, Cultura y Deporte, 2013, p. 52).

En Chile, el programa de estudio de sexto básico señala que las nociones de razón y porcentaje son conceptos que permiten comprender de forma más profunda las fracciones y los decimales, y que proveerán al alumnado de herramientas que les permitan resolver problemas en contextos cotidianos, en particular del área económica (Mineduc, 2013).

El porcentaje adquiere relevancia en las directrices curriculares presentadas, donde la comprensión de esta noción enriquece la formación de los escolares y su preparación para desenvolverse de manera competente en la sociedad, haciendo uso de las matemáticas de forma efectiva.

El Informe Cockcroft (1985), daba cuenta de las dificultades que tenía la ciudadanía para desenvolverse competentemente con el porcentaje. En los últimos treinta años, otros estudios como los de Parker y Leinhardt (1995), Maza (2000), Zurbano (2002), Mendoza (2007) y Maz-Machado y Gutiérrez (2008) informan sobre resultados similares. Estos trabajos afirman que, a pesar de que la noción de porcentaje es de conocimiento público y de cultura general, en diferentes ámbitos de la cotidianidad, hay dificultades que subyacen a su significado, es decir, a su comprensión, interpretación y aplicación.

Aunque la presencia del concepto porcentaje en la vida diaria es patente, resulta necesario preguntarse si para los escolares ¿es comprensible el o los significados que sobre el porcentaje transmite una determinada información?, ¿cuáles son los conceptos, representaciones y modos de uso que sobre el porcentaje internalizan los estudiantes tras un primer acercamiento escolar a este concepto? 


\subsection{Objetivos del estudio}

Este estudio tiene como objetivo general indagar y describir los significados del concepto de porcentaje que han internalizado y manifiestan estudiantes chilenos de Educación Primaria tras un primer acercamiento escolar a esta noción. Este objetivo lo abordamos en términos de tres componentes del significado de un concepto matemático escolar, que son la estructura conceptual en que se ubica, los sistemas de representación que lo expresan y los sentidos y modos de uso con que se emplean.

Del objetivo general, surgen en el estudio los siguientes objetivos específicos:

1. Construir un cuestionario semántico que recoja indicios de expresiones y representaciones sobre la noción de porcentaje que expresan los estudiantes de Educación Primaria.

2. Identificar y categorizar los sentidos y modos de uso empleados por los estudiantes al expresar sus ideas acerca del porcentaje.

3. Identificar y describir los modos de representación que utiliza el alumnado para referirse al porcentaje.

4. Interpretar y describir los conceptos, relaciones y propiedades puestos de manifiesto por el alumnado al referirse a la noción de porcentaje. 


\section{CAPÍTULO 2: FUNDAMENTACIÓN TEÓRICA}

\subsection{Antecedentes de investigaciones sobre el porcentaje}

En una revisión sobre los estudios que han abordado el concepto de porcentaje encontramos los siguientes:

Parker y Leinhardt (1995), presentan una completa revisión sobre las investigaciones realizadas en torno a la idea de porcentaje con el fin de responder a la pregunta ¿por qué es difícil el tanto por ciento? Estos autores concluyen que: (a) la noción de porcentaje se ha desarrollado con el tiempo a partir de una sencilla expresión pragmática de "tantos de esto para 100 de que" en un lenguaje matemático que envuelve a las comparaciones proporcionales y funciones racionales; (b) el porcentaje es difícil porque a pesar de su estructura, es un concepto matemático y socialmente complejo, ambiguo ya que parece tener varios significados a la vez; (c) el porcentaje utiliza una forma lingüística muy concisa, es decir, las características relacionales de cantidades que, generalmente, están ocultas en la notación comprimida; y (d) el porcentaje es difícil y no es bien enseñado, de manera que los estudiantes a menudo tienen una visión limitada del concepto.

Lee (1998), presenta un estudio en el que examinó la base de conocimientos de profesores en formación, sus enfoques a los problemas de cálculo y sus resultados en problemas de porcentaje en contexto. Los resultados presentaron una deficitaria comprensión del concepto "por ciento". Específicamente, los datos mostraron que resultaba más fácil realizar problemas de cálculo que explicar el concepto de porcentaje, donde muchos de los profesores en formación no eran capaces de idear un enfoque alternativo a un problema de cálculo. Además, los participantes tuvieron dificultades para aplicar el concepto correctamente en su contexto.

Al igual que los profesores en formación en el estudio de Parker (1994), los participantes del estudio de Lee, carecen del sentido de comparaciones de cantidades. Por otra parte, no miraron reflexivamente sus respuestas ni vincularon las situaciones 
problemáticas con sus experiencias cotidianas. Concluyeron que hay una necesidad de enriquecer y ampliar la base de conocimientos de la noción de por ciento en los profesores en formación, enfatizando sobre la interpretación proporcional del porcentaje en forma contextualizada.

Maza (2000), aborda el tema de la formulación y resolución de problemas de porcentaje en estudiantes universitarios de primer curso de Magisterio. El autor logra describir y categorizar las estrategias de resolución empleadas, la relación entre las características estructurales y las estrategias de resolución, así como los errores más frecuentes. Además, describe las características estructurales de los problemas formulados por los sujetos de investigación realizando un análisis de los mismos.

Zurbano (2002), plantea un estudio exploratorio acerca de la interpretación de ciertas situaciones porcentuales por parte de alumnos universitarios y maestros en ejercicio. Busca probar como hipótesis que la convivencia diaria con los porcentajes, en distintos ámbitos, no supone una especial destreza en su manejo por parte de los ciudadanos. Sus conclusiones apuntan a la necesidad de tratar los porcentajes de manera específica en los planes formativos, de manera sistemática, acudiendo a situaciones matemáticas que hagan referencia a contextos relevantes para la vida de los alumnos, contribuyendo a que los ciudadanos puedan llegar a interpretar correctamente la información que reciben en forma de porcentaje.

Mendoza (2007), en su tesis de maestría realiza un estudio didáctico de la noción de porcentaje de la que derivan dos artículos que hemos identificado. En el primero de ellos (Mendoza y Block, 2010), se desarrolla un análisis del uso que estudiantes de secundaria hacen de las razones, las fracciones y los decimales para resolver situaciones de porcentaje. En este trabajo se enfatiza el hecho de que la polisemia del concepto conduce a la ambigüedad. En el análisis realizado a las interpretaciones de los estudiantes los autores identifican el porcentaje como: razón expresada con dos números, como fracción, como operador decimal. Además, estimulan la reflexión en torno a los procesos de enseñanza y aprendizaje de la noción de porcentaje y el difícil transito que realizan los estudiantes entre los distintos modos de interpretación. En el segundo artículo (Mendoza, 2009), aborda la 
noción de porcentaje, los procedimientos, errores e interpretaciones que dan estudiantes de secundaria al resolver situaciones que impliquen porcentajes.

Maz y Gutiérrez (2008), buscaron determinar en qué errores incurren y cuáles son las situaciones de porcentaje que presentan un mayor grado de dificultad a estudiantes de Magisterio, logrando establecer tres tipos de errores: cien como unidad, incremento ordinal y suma nominal.

Estas y otras investigaciones previas aportan evidencia empírica de las dificultades que subyacen a la comprensión de la noción de porcentaje en poblaciones de distintas edades y características. Esta complejidad se atribuye, en parte, a la polisemia de este particular concepto, que presenta varios modos de interpretación. Es por ello, que nos motiva focalizar la atención de este estudio en identificar los significados que son asimilados por los estudiantes de Educación Primaria tras un primer acercamiento escolar a esta noción, considerando un importante periodo de latencia, ya que estas ideas constituyen la base de consolidación de sus conocimientos.

\subsection{Los contenidos sobre porcentaje en el currículo chileno}

Las Bases Curriculares para la Educación Básica en Chile (Mineduc, 2012), indican cuáles son los contenidos comunes para todos los alumnos y alumnas de primero a sexto básico del país. Tienen un carácter obligatorio y son el referente respecto del cual se construyen los programas del Ministerio de Educación (Mineduc), los programas de estudio propios de algunos establecimientos, los planes de estudio, los estándares de aprendizaje y la prueba SIMCE (prueba nacional que mide los logros de aprendizaje de los estudiantes chilenos).

Las Bases Curriculares establecen Objetivos de Aprendizaje (OA) que definen los desempeños mínimos que se espera que todos los estudiantes logren en cada asignatura y en cada nivel de enseñanza. En el caso de matemáticas, los contenidos se estructuran en cinco ejes: (a) números y operaciones; (b) patrones y álgebra; (c) geometría; (d) medición y (e) datos y probabilidad. Los contenidos se trabajan con grado de complejidad creciente para cada nivel educativo. 
En el caso específico de la noción de porcentaje en este documento curricular, esta se encuentra entre los conceptos y estructuras del eje de números y operaciones a partir de $6^{0}$ año de educación básica. Se señala el objetivo "demostrar que comprenden el concepto de porcentaje de manera concreta, pictórica y simbólica, de forma manual y/o usando software educativo" (Mineduc, 2013, p. 42).

Se introduce un primer significado para el porcentaje en el currículo, enfatizando tres aspectos: su comprensión, su representación y su uso. En los cursos posteriores se continúa el trabajo y profundización sobre este y otros temas asociados, sin embargo, hemos puesto nuestro foco de atención en indagar qué ha internalizado el alumnado tras un primer tratamiento escolar de esta noción.

\subsection{Significado de un concepto matemático escolar}

Frege (1998), aborda la noción de significado de un término o de un concepto, mediante la terna signo, sentido y referencia, en la cual, la referencia alude al objeto designado, el signo se refiere a las representaciones que lo muestran y el sentido, al modo de su presentación o de uso. Frege explicita que una referencia puede tener más de un sentido, que al signo le corresponde un sentido determinado y a éste, a su vez, una referencia determinada, mientras que a una referencia no le pertenece sólo un signo (Frege y Valdés, 1998).

De lo anterior se desprende la relación entre las tres componentes de la terna semántica en la configuración del significado que se muestran en la figura 1.

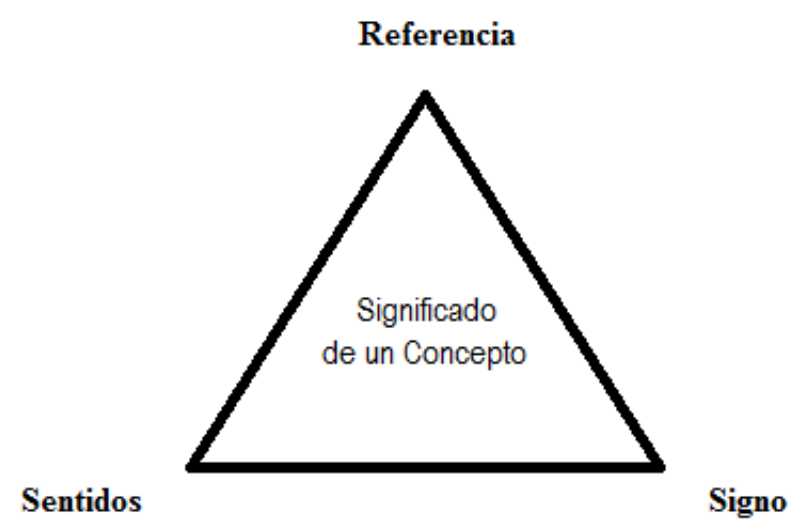

Figura 1. Terna semántica de Frege 
El autor resalta la idea de que una referencia puede tener más de un sentido, lo que afirma la pluralidad de significados de un determinado concepto, también es posible representar una misma referencia mediante diversos signos, los que aluden a variados sentidos o modos de uso.

Basados en las ideas de Frege, entendemos que el significado de un concepto matemático escolar se establece por tres componentes: una estructura formal (conceptos, propiedades y relaciones), por unos símbolos y notaciones que lo representan y expresan, junto con unas reglas de procesamiento y conversión, y por unas situaciones, contextos y modos de uso que le dan sentido y emplean (Rico, Flores y Ruiz-Hidalgo, 2015), elementos que dan respuesta a tres cuestiones fundamentales: cómo se define, cómo se expresa y para qué se usa. La figura 2, grafica la terna semántica de un concepto matemático escolar.

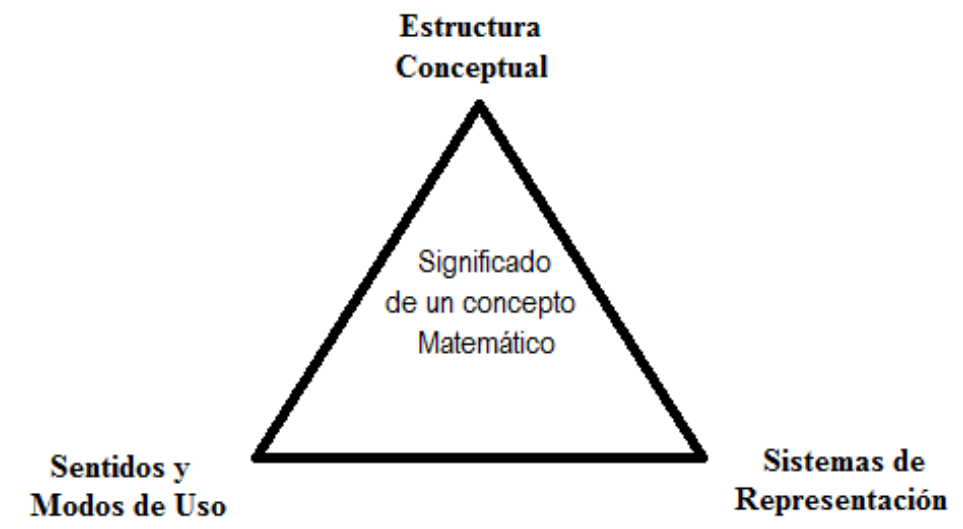

Figura 2. Terna semántica del significado de un concepto matemático escolar

La estructura conceptual considera las definiciones de los conceptos que incluye, sus propiedades, relaciones y procedimientos, atendiendo a sus propiedades formales y su funcionalidad cognitiva (Lupiáñez, 2013).

Siguiendo al mismo autor, los sistemas de representación consideran los diferentes símbolos, notaciones y gráficos, junto con sus reglas de composición y procesamiento, con las que se representa un concepto, sus relaciones con otros conceptos y procedimientos. Las representaciones pueden ser simbólicas, gráficas, numéricas o verbales. 
La polisemia de los conceptos nos permite entender que ellos tendrán distintos sentidos y modos de uso. Desde una aproximación semántica, el sentido de un concepto matemático escolar forma parte de su significado y se centra en los términos, contextos, fenómenos, situaciones que muestran los modos de uso de dicho concepto (Rico et al., 2015).

Una de las dificultades que subyace al significado de un concepto matemático deriva justamente de los múltiples usos y sentidos que se le pueden atribuir. Cuando se habla del sentido de un concepto, en nuestro caso el porcentaje, estaría relacionado con su presencia en situaciones de uso cotidiano. En una interpretación más amplia:

“... el sentido de un conocimiento varía, evoluciona, cambia de alumno a alumno o para un mismo alumno de un momento a otro ante distintas situaciones... Sin embargo, pese a que la construcción del sentido es dialéctica, móvil y sumamente sutil, es posible pensar, desde la enseñanza, qué sentido de las operaciones se están propiciando a raíz de los problemas que se plantean a los alumnos, a raíz de los procedimientos que se asegura que dominen, a raiz de las representaciones que se movilizan..." (Dirección de Currículum, 1994, pp. 19-20).

Parker y Leinhardt (1995), señalan que el porcentaje tiene propiedades de número, de la relación parte-todo, de razón, y al mismo tiempo sirve, ya sea como una función que crea otros números o como un estadístico que describe una relación entre dos números. En este trabajo nos interesa descubrir cuáles son las ideas relativas al porcentaje que cimientan bases del aprendizaje de este concepto matemático, aquellas que perduran después del primer acercamiento escolar, esas ideas con las que los estudiantes se expresan en situaciones donde tienen que pensar sobre el porcentaje.

\subsection{Análisis de contenido del concepto de porcentaje}

El análisis de contenido es un método que se centra en analizar, describir y establecer los diferentes significados que tienen las nociones involucradas en algún concepto o estructura matemática (Lupiáñez, 2013). En este estudio, se realiza un análisis de contenido sobre el concepto de porcentaje para establecer su significado, clarificar las 
categorías de análisis, y como referente para interpretar las nociones parciales que se recogen de los estudiantes mediante el cuestionario.

El análisis de contenido se inicia estableciendo la organización conceptual, procedimental y las relaciones del concepto en cuestión, tal como se establece en las directrices curriculares.

Se recurre a la historia de la matemática con el fin de reconstruir un panorama general de la evolución del significado del concepto, intentando determinar las situaciones que estuvieron en su origen y sobre las cuales ha surgido, se revisan y comparan los diferentes sistemas de representación empleados y su evolución (Lupiáñez, 2013).

Luego, se examina su estructura conceptual determinando los elementos de los campos conceptual (hechos, conceptos y estructuras) y procedimental (destrezas, razonamientos y estrategias) que caracterizan el contenido matemático analizado.

Se explicitan los diferentes sistemas de representación y se analizan los sentidos y modos de uso con los que se precisan los términos, situaciones, contextos y fenómenos que dan sentido al contenido considerado.

Nos interesa indagar sobre el porcentaje porque es uno de los conceptos matemáticos de mayor uso en la cotidianidad, en distinto ámbitos (comercial, científico, matemático, social, medios de comunicación entre otros), siendo de gran importancia que los ciudadanos manejen nociones respecto a su significado, es decir, a su definición, a su representación y a sus diferentes sentidos y modos de uso.

\subsubsection{Sentidos y modos de uso del porcentaje}

Rico y Díez-Lozano (2011), precisan que en el ámbito escolar, un concepto matemático dispone de una variedad de significados, ya que un mismo concepto admite diversos referentes, distintas notaciones o representaciones y una pluralidad de sentidos, los cuales determinan sus posibles significados. Los distintos modos de uso dados a un concepto, delimitan su sentido y por ende, su significado en términos de la terna semántica de un concepto matemático escolar. 
Las diferentes formas en que se utiliza una expresión o concepto en el lenguaje y las situaciones cotidianas, estimulan el pensamiento en pos de hacer que emerjan los significados y las relaciones que se han internalizado, es decir, el registro matemático permite nombrar los conceptos matemáticos, lo cual hace pensar en el significado o en la red interconectada de ideas que indican dicho concepto (Lee, 2010).

Comenzamos el estudio del significado del concepto porcentaje a partir de su sentido o modos de uso. Este componente lo abordamos mediante cuatro elementos que son: los términos empleados para referirse a una determinada noción, los fenómenos, las situaciones y los contextos.

\section{a) Términos}

Moliner (2013), precisa que para referirse al porcentaje en la vida cotidiana se pueden usar sinónimos tales como: por ciento o tanto por ciento. Otra variante sería el tanto porcentual.

Siguiendo a la Real Academia Española (2014), el porcentaje se define como la “proporción que toma como referencia el número 100”. De esta definición deriva el término por ciento, que se entiende como "de cada ciento" y se representa con el signo "\%”. Así por ejemplo, la expresión 15\% significaría "quince de cada 100", pero es sólo una forma simple de comprensión del porcentaje.

El tanto por ciento de un número es una o varias de las cien partes iguales en que se puede dividir dicho número, es decir, uno o varios centésimos (Chávez y León, 2001).

Moliner (2007), define el tanto por ciento como número de cualquier clase de cosas que se toma o se considera, de cada cien de ellas; agrega "el interés producido por cien unidades monetarias en la unidad de tiempo, que es un año o la que se especifica, por ejemplo: al dos por ciento mensual" (p. 2818). En este caso, al referirse a una comparación de unidades diferentes, nos encontramos frente a una interpretación del porcentaje en una proporcionalidad compuesta $\mathrm{o}$, alternativamente, como tasa. 
García (1992), en su Diccionario de Términos Matemáticos, asocia el porcentaje al tanto por ciento, pero complementa indicando que se refiere a la cantidad que hay que pagar por cada cien unidades, si se piden prestadas, o qué cobrar si se prestan. En esta definición se desprende una situación de uso preferente del porcentaje, lo cual reafirma que el significado de un concepto viene dado también por los modos de uso que éste tenga y la magnitud con la cual se utiliza.

Desde ámbitos científicos como la física y la química, el porcentaje o tanto por ciento, se entiende como proporción de una cantidad respecto a una centena de otra; comúnmente se utiliza como forma de expresar la concentración de una disolución, es decir, los gramos de soluto disueltos en 100g. de disolución (Arnau et al., 1997), que es una razón entre dos cantidades de peso, la segunda de las cuales es 100.

La expresión "por ciento" precedido de un numeral cardinal o por tanto, expresa que de un todo, que se supone dividido en cien partes, se toma o considera el número de ellas indicado por el numeral. La variación "porcentual", como adjetivo, se aplica a la composición, distribución, etc. calculada y expresada en tantos por ciento (Segura, 2010).

Es digno de aclarar que el porcentaje o tanto por ciento, es la forma más extendida en todo el ámbito hispánico, aunque también se usa a veces el sinónimo "porciento", que se escribe siempre con una sola palabra a diferencia de la locución "por ciento", usada en la expresión del porcentaje, que se escribe siempre con dos palabras. Por ejemplo, uno por ciento.

\section{b) Fenómenos}

En este estudio, abordamos la fenomenología desde una aproximación histórica en la que revisamos antecedentes que permiten identificar las circunstancias en las que surgió y se desarrolló el concepto de nuestro interés.

El porcentaje comenzó con la idea de privilegiar una base particular (100) de intereses e impuestos. De la revisión histórica realizada, que se adjunta en el Anexo A, destacamos que fueron los fenómenos comerciales y mercantiles que originaron el surgimiento y evolución de la noción de porcentaje, adquiriendo importancia por el uso que 
se le dio. La terminología y símbolo que usamos hoy en día en occidente para el porcentaje tiene su origen en las actividades comerciales medievales y renacentistas propias de la Italia mercantil.

\section{c) Situaciones}

Entendemos por situaciones, aquella parte del mundo real en la cual se sitúa una tarea o actividad matemática. Las situaciones destacan el medio en el cual una determinada estructura matemática tiene un uso regular y viene dada por una mención al medio en el cual se enmarcan problemas y cuestiones matemáticas que pueden encontrar los ciudadanos y que se proponen a los estudiantes para centrar su trabajo (Lupiáñez, 2013).

En éste trabajo consideraremos las situaciones propuestas en el marco del Proyecto PISA (OCDE, 2005), es decir, situaciones personales, educativas o laborales, públicas y científicas.

El uso del porcentaje en las votaciones electorales o las tablas y gráficos que se utilizan en la prensa son ejemplo de situaciones públicas, mientras una situación del quehacer científico sería el uso de porcentajes para referirse a las disoluciones. Los problemas y tareas escolares y el cálculo de un descuento que se realiza en una tienda ejemplifican las situaciones educativas y laborales respectivamente, mientras que estimar el porcentaje de dinero con que se paga una deuda sería ejemplo de una situación personal.

\section{d) Contextos}

Un contexto matemático es un marco en el cual conceptos y estructuras atienden unas funciones, responden a unas necesidades como instrumentos de conocimiento (Rico y Lupiáñez, 2008). Los contextos se reconocen porque muestran posibles respuestas a la pregunta ¿para qué se usan estas nociones?, el contexto refiere el sentido con el que se usan los conceptos en una o varias situaciones (Lupiáñez, 2013).

El porcentaje se adecúa a contextos como expresar relaciones parte-todo, que pueden ser aditivas o multiplicativas dependiendo de la relación que se establezca entre cantidades. En este caso se refiere a una relación multiplicativa entre cantidades de una 
misma magnitud; por ello, el porcentaje actúa como razón geométrica. Por tanto a\% equivale a la expresión $\frac{a}{100}$, entendiendo que se refiere a tantas partes de una cantidad de referencia que ha sido dividida en cien partes iguales y se han tomado las indicadas por el valor de $a$. Cuando el porcentaje se presenta en la forma $a \%$ de $b, b$ sería una cantidad absoluta, llamada cantidad de referencia.

Otros contextos son expresar proporción entre cantidades, realizar cambios como en el ámbito financiero que se utiliza para referirse a las variaciones de índices comerciales o bien descuentos e intereses aplicados a algún producto. También se utiliza en contextos de comparación, es decir que mediante el uso de porcentajes se puede establecer cuánto más o cuánto menos es una cantidad respecto a otra.

En los distintos sentidos y modos de uso del porcentaje, se puede emplear otros términos relacionados, que si bien no son sinónimos directos, complementan las diferentes modalidades de uso, entre los que encontramos:

- Ciento por ciento o bien, cien por ciento, como expresiones de totalidad.

- Ciento por uno, al aludir que se ha cosechado fruto cien veces mayor que lo sembrado.

- Para expresar que se duplicaron o triplicaron las ganancias (200\% de ganancia).

- Expresa información en forma porcentual (porcentajes como modo de representación)

- Comisión, para expresar el porcentaje obtenido por la venta de algo

- Tasa, para referirse a un porcentaje de beneficio.

- Como descuento, expresando la disminución respecto a un valor de referencia.

- Ley, entendida como peso, medida, proporción o porcentaje.

- Razón, para referirse a la comparación de cantidades de la misma magnitud.

\subsubsection{Sistemas de representación del porcentaje}

Castro y Castro (1997), señalan que las representaciones son las notaciones simbólicas o gráficas, específicas para cada noción, mediante las que se expresan los conceptos y procedimientos matemáticos así como sus características y propiedades más 
relevantes. En educación matemática, múltiples y variadas representaciones sobre los contenidos matemáticos escolares, enriquecen los procesos de su enseñanza y aprendizaje.

Las representaciones matemáticas se han entendido, en sentido amplio, como todas aquellas expresiones —notaciones, símbolos o gráficos- que hacen presentes los conceptos y procedimientos matemáticos y con las cuales los sujetos particulares abordan e interactúan con el conocimiento, es decir, registran y comunican su conocimiento, piensan sobre las matemáticas. Mediante el trabajo con las representaciones las personas asignan y comparten significados y trabajan con las estructuras matemáticas (Rico, 2009, p. 3).

Entre los sistemas de representación que contribuyen a establecer el significado de la noción de porcentaje destacan: (a) las notaciones simbólicas; (b) las expresiones verbales; y (c) las representaciones gráficas.

En los sistemas de representación simbólicos, las reglas sintácticas de la notación porcentual establecen que debe escribirse un número, entero o decimal, seguido del símbolo $\%$. Este símbolo es el resultado de la evolución histórica de las formas que se utilizaban para denotar el per cento, como se detalla en el Anexo A que trata la evolución histórica del porcentaje y su símbolo.

De manera excepcional se acepta que la enumeración de dos o más porcentajes incluya el símbolo \% detrás del último de ellos: por ejemplo, 5, 15 y $30 \%$.

Gairín y Sancho (2002), indican que si se considera la expresión porcentual como un ente numérico abstracto o como una medida, se evalúa semánticamente como un operador que actúa sobre un número o una cantidad de magnitud y se puede expresar como sigue:

$$
a \%(n)=(a * n) \div 100
$$

Valverde (2013), señala que el porcentaje se representa por la combinación de un numeral y el símbolo \% y que además, se puede escribir en notación decimal o como expresión fraccionaria. A lo anterior, añadimos la representación como razón en la forma $a$ : $b$ tal como se ejemplifica en la tabla 1 . 
Tabla 1. Notaciones y símbolos para el porcentaje

\begin{tabular}{cccc}
\hline Como Porcentaje & Como Fracción & Como Decimal & Como Razón \\
\hline $15 \%$ & $\frac{15}{100}$ & 0,15 & $15: 100$
\end{tabular}

Quince por ciento Quince de cada cien Quince centésimos Quince es a cien

En el sistema de representación verbal, la forma específica para referirse al porcentaje de manera escrita que detalla la RAE se ha incluido en el Anexo B. Se reconoce también la representación numérica-verbal en la que se combina un numeral con la expresión "por ciento" u otras variantes. Por ejemplo: "veinticinco por ciento", "15 por ciento".

El sistema de representación grafico sobre el porcentaje incluye diagramas continuos de área con regiones circulares o cuadradas, que se dividen en tantas partes iguales o bien, cuadriculas de 10x10 en las que se colorean tantas centésimas partes como sean necesarias. La figura 3 ejemplifica algunas representaciones gráficas sobre el porcentaje.

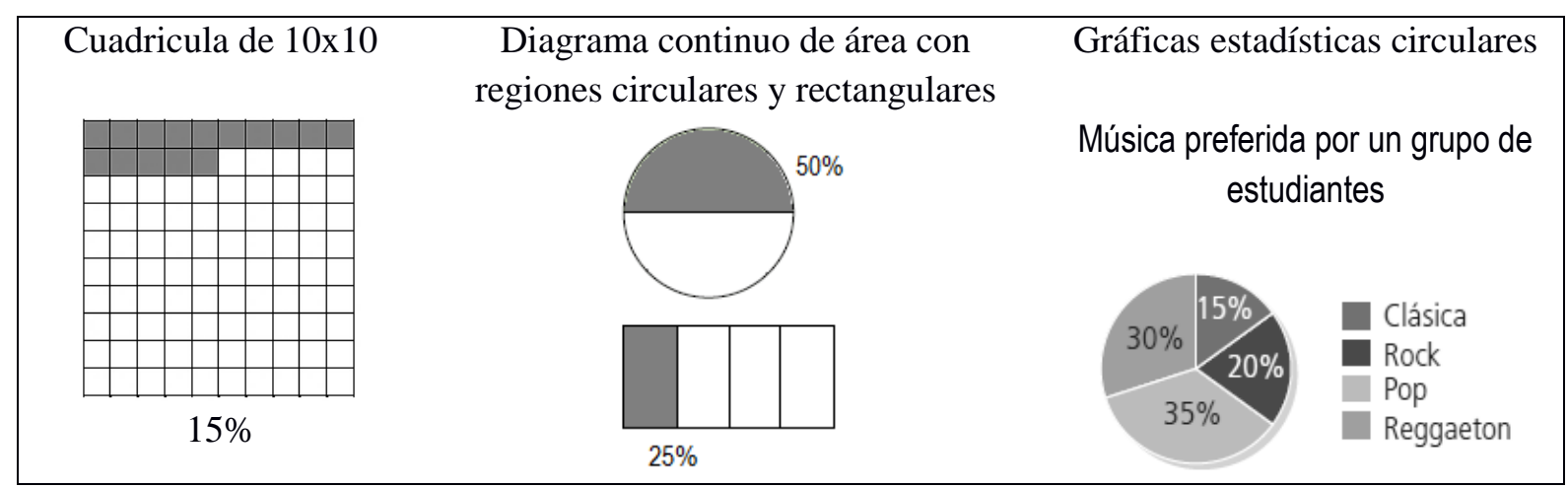

Figura 3. Representaciones gráficas del porcentaje

Resaltan los gráficos circulares o también llamados diagramas de sectores para representar datos estadísticos mediante porcentajes, los que se caracterizan por estar divididos en sectores proporcionales al porcentaje que representan. 
También se presenta el porcentaje como un punto decimal con dos decimales en el intervalo $[0,1]$ en la recta real, o como un punto entero del intervalo $[0,100]$ de la recta numérica discreta como se muestran a continuación en la figura 4.

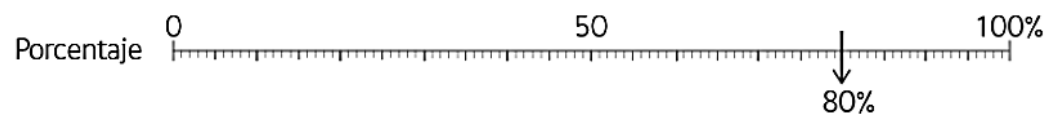

Figura 4. Representación de porcentajes en la recta numérica discreta

\subsubsection{Estructura conceptual del porcentaje}

En el análisis de la estructura conceptual se realiza una revisión de los contenidos matemáticos escolares, es decir, desde la consideración de su aprendizaje y enseñanza, precisando sus campos conceptual y procedimental.

Los conceptos son la sustancia de nuestro conocimiento, son aquello con lo que pensamos (Rico y Lupiáñez, 2008). En el análisis del campo conceptual se distinguen tres niveles: hechos, conceptos y estructuras. Los hechos constituyen el nivel básico de complejidad conceptual, y se pueden diferenciar en términos, notaciones, convenios o resultados.

Siguiendo a los mismos autores, los conceptos se consideran formados por unidades de información (hechos) conectados entre sí mediante relaciones y propiedades, se pueden entender como redes de conocimiento interconectadas mediante argumentaciones que forman parte de un sistema. A su vez, las estructuras conceptuales, se constituyen como redes de conceptos matemáticos organizados e interconectados.

El porcentaje parece ser un concepto privilegiado cuyo análisis identifica diferentes significados y que se ubica en diversas estructuras matemáticas. Su vinculación con la noción de razón, con las fracciones y los decimales surge de manera natural mediante su definición, algunas de sus interpretaciones y modos de representación. 
Entendemos el porcentaje como un tipo especial de razón geométrica que expresa bien una relación dentro de un conjunto numérico, o bien entre cantidades de una magnitud, que puede ser discreta o continua. Gairín y Sancho (2002), definen el porcentaje como una razón geométrica, es decir, como el cociente indicado de cantidades de una misma magnitud en que la cantidad del denominador $-\mathrm{o}$ consecuente - mide 100. Es decir, un porcentaje es el cociente entre una cantidad "c" de una magnitud y 100 unidades de esa misma magnitud: $\mathrm{c} / 100$.

Entonces, el tanto por ciento (\%) es una razón, es decir, el cociente indicado de las medidas de dos cantidades que se refieren a una misma magnitud expresados con la misma unidad. La relación viene dada por sus medidas, la primera cantidad mide siempre 100, mientras que la segunda cantidad tiene por medida el número que aparece en el tanto por ciento (Fernández y Segovia, 2011). En términos generales es una relación de proporcionalidad de una magnitud consigo misma.

El concepto de porcentaje se ubica en el campo de las estructuras numéricas escolares, del conjunto de los números racionales y de sus subconjuntos relevantes. En este campo se distinguen dos estructuras básicas a las que el porcentaje se ajusta, la estructura aditiva y la estructura multiplicativa, según la relación que se establezca entre las cantidades participantes.

Los porcentajes, como fracciones de igual denominador, operan aditivamente; dando lugar a una estructura aditiva propia. Como en otras estructuras numéricas aditivas se distinguen tres relaciones básicas entre los porcentajes: (a) la relación parte-todo; (b) las relación de cambio, en las que se produce aumento o disminución respecto a una cantidad; y (c) la relación de comparación en las que se puede establecer una comparación en términos de "mayor que" o "menor que" respecto a una cantidad inicial. En esta estructura también se distinguen relaciones aditivas relativas, es decir, números con signos que, sin interpretarse como números enteros, aluden a quitar o agregar un determinado porcentaje. En el estudio de los porcentajes encontramos estos tres tipos de relaciones numéricas, que muestran distintos significados aditivos de los porcentajes. 
Como relación multiplicativa, el porcentaje se entiende como una cantidad que se descompone en cien partes iguales, cada una de ellas relacionada multiplicativamente con el total. En este caso se identifican tres relaciones: (a) la relación parte-todo, entendidas como $n$ partes iguales de un total; (b) la relación parte-parte que se da al comparar cantidades (cuánto por ciento es mayor o menor la una que la otra); y (c) el porcentaje como un operador sobre cantidades, que se usa para establecer relaciones multiplicativas entre cantidades de la misma magnitud.

El resultado de la medida también es una expresión porcentual, como exponen Gairín y Sancho (2002), en este caso,

...el porcentaje conlleva la comparación de los resultados de la medida de dos cantidades de magnitud: la medida de una parte de la cantidad de magnitud total que se considera y la medida de la totalidad de dicha cantidad de magnitud, donde el porcentaje debe ser menor o igual a 100; o bien, la medida de dos cantidades de magnitud, de la misma naturaleza, no incluidas la una en la otra, donde tienen cabida los porcentajes mayores a 100 (pp.161-162).

En el campo de conocimiento procedimental, se distinguen tres niveles diferentes: destrezas, razonamientos y estrategias. Rico y Lupiáñez (2008), señalan que las destrezas suponen el dominio de los hechos y sus procesamientos usuales, que se pueden desarrollar de acuerdo con rutinas secuenciadas como, por ejemplo, la transformación de una expresión simbólica en otra (Ruiz-Hidalgo y Fernández-Plaza, 2013). Los razonamientos suponen un procesamiento entre conceptos, modos de derivar unos de otros, distinguiendo tipos de razonamientos. Las estrategias serían aquellos procedimientos o reglas de acción que permiten obtener una conclusión o responder a una cuestión haciendo uso de las relaciones, conceptos y diversidad de sistemas de representación que se dan en una determinada estructura conceptual.

Algunas de las destrezas vinculadas al concepto de porcentaje son el cálculo, mental y/o escrito, el dominio de las equivalencias entre los distintos modos de representación y el uso de las calculadora. 
Entra las estrategias tenemos: (a) el cálculo mental de porcentajes como el 50\% o el $25 \%$ asociando a la mitad y la mitad de la mitad respectivamente; (b) cálculos de otros porcentajes asociando a su fracción equivalente; (c) cálculo de porcentajes dividiendo, por ejemplo, dividir por 5 una determinada cantidad para calcular el 20\%; (d) calculo escrito de porcentajes mediante uso de regla de tres simple y (e) cálculo de porcentajes multiplicando por el decimal equivalente al porcentaje solicitado.

Ejemplos de razonamientos deductivo, inductivo y analógico para la noción de porcentaje se presentan en la tabla 2.

Tabla 2. Razonamientos sobre el concepto de porcentaje

\begin{tabular}{ll}
\hline & \multicolumn{1}{c}{ Razonamientos } \\
\hline Deductivo & Al deducir que el 50\% se puede determinar dividiendo en 2, o que si se calcula \\
& un porcentaje menor que el $100 \%$, resultará un valor menor que el valor inicial \\
& $\begin{array}{l}\text { de referencia, mientras que si se determina un porcentaje mayor que 100\%, se } \\
\text { obtendrá un mayor valor que el inicial. }\end{array}$ \\
\hline Inductivo & Al generalizar que el 10\% de cualquier número se obtiene ubicando una coma \\
& antes de la última cifra del número. \\
\hline Analógico & $\begin{array}{l}\text { Al resolver diferentes situaciones que impliquen porcentajes a partir de otros } \\
\text { situaciones resueltas anteriormente. }\end{array}$ \\
\hline
\end{tabular}

Se reconocen tres tipos de situaciones problemas que implican estos razonamientos: (a) determinar el porciento de un número; (b) determinar qué porciento es un número de otro, o bien, (c) determinar un número conociendo un porciento de él.

Los diferentes aspectos detallados dan cuenta de la particularidad de la noción de porcentaje, los conceptos, propiedades y operaciones que subyacen a este tópico de las matemáticas escolares que parece tan trivial, sin embargo, esconde una riqueza de relaciones conceptuales con otras nociones como lo son las fracciones, los decimales y las razones que, al trabajarlas en el ámbito escolar, se complementan para potenciar una mejor comprensión.

El análisis conceptual realizado, muestra que el concepto porcentaje es empleado en distintas situaciones, mediante distintas notaciones y símbolos y respondiendo a variados 
contextos. Además, dispone de variados sistemas de representación que resaltan sus cualidades y relaciones con otros conceptos destacados de las estructuras y relaciones de las cuales forma parte.

Sus múltiples usos en la cotidianidad demanda comprender una variedad de significados, por tal razón consideramos importante escudriñar las expresiones manifestadas por el alumnado respecto al porcentaje, con el fin de detectar e identificar las concepciones, es decir, aquellas "parcelas" de significado (significados parciales) que emergen de las respuestas (verbales, escritas, gráficas, gestuales, etc.) de los estudiantes ante las demandas que plantean tareas particulares que responden a una determinada caracterización, descripción o definición de un concepto (Fernández-Plaza, CastroRodríguez, Estrella, Martín-Fernández, Rico, Ruiz-Hidalgo y Vílchez-Marín, en prensa). 


\section{CAPÍTULO 3: MARCO METODOLÓGICO}

\subsection{Tipo de estudio y descripción general}

El estudio llevado a cabo es de tipo cualitativo, con carácter exploratorio. Sigue un diseño transversal que se caracteriza por recolectar datos en un determinado momento, en los términos planteados por Hernández, Fernández y Baptista (2007). Responde a un propósito descriptivo que busca registrar y pormenorizar las características de un fenómeno y sus elementos, así como las relaciones que se dan entre ellos (Johnson y Christensen, 2014). El método de recogida de datos es por encuesta, específicamente un cuestionario semántico especialmente elaborado para los fines de éste estudio que se detallan más adelante.

En el contexto de este estudio y a partir de los componentes del significado de un concepto matemático escolar, vistos en el capítulo anterior, es posible establecer categorías para organizar y analizar las respuestas proporcionadas por los estudiantes.

\subsection{Los sujetos}

En el estudio participaron 108 estudiantes chilenos, que cursan séptimo año básico en centros de áreas urbanas. Estos sujetos han sido seleccionados intencionalmente, por disponibilidad, buscando que cumplan ciertas características, tales como:

- Cursar séptimo año de enseñanza básica en centros educativos chilenos.

- Haber estudiado en el curso anterior el concepto de porcentaje de manera introductoria y por primera vez, según las indicaciones de las directrices curriculares.

- No haber estudiado nuevamente el concepto porcentaje en el transcurso del presente año escolar (2016).

Específicamente, los sujetos corresponden a tres colegios, los cuales accedieron a participar del estudio. En la tabla 3, se detalla el número de sujetos de cada centro junto con 
la cantidad total de estudiantes que conforman la muestra. En el Anexo C, se describen brevemente estos centros.

Tabla 3. Colegios y número de participantes

\begin{tabular}{lcc}
\hline \multicolumn{1}{c}{ Colegio } & Cursos & $\begin{array}{c}\text { Cantidad de } \\
\text { estudiantes }\end{array}$ \\
\hline A. Colegio Augusto Winter (Temuco) & 1 & 33 \\
B. Colegio Nuestra Señora del Carmen (Padre las Casas) & 2 & 39 \\
C. Escuela No12 Vista Verde (Temuco) & 1 & 36 \\
Total & 4 & 108 \\
\hline
\end{tabular}

Del total de participantes, 8 estudiantes no responden a ninguna pregunta, razón por la que no se consideran parte del estudio, quedando finalmente una muestra de 100 participantes.

\subsection{El instrumento}

Para la recolección de datos se utilizó un cuestionario semántico, con 8 enunciados de respuesta abierta, que buscan recoger información que se pueda interpretar en términos de las componentes del significado de la noción de porcentaje, es decir, de su estructura conceptual, de los sistemas de representación y de los sentidos y modos de uso de dicho concepto.

El cuestionario recoge expresiones escritas o gráficas que los estudiantes proporcionan de manera natural al solicitarles determinados juicios sobre la noción de porcentaje. Considerando los planteamientos de Pimm (2000), la escritura exterioriza el pensamiento, aún más que el habla, al exigir una concordancia de ideas y en esa línea, nuestro análisis se centra en las producciones escritas que suministran los estudiantes y que reunimos mediante el cuestionario semántico.

El proceso de diseño y elaboración del cuestionario se detalla en el Anexo D donde se presentan los objetivos de cada una de las preguntas planteadas, las distintas fases de elaboración, su revisión, valoración por expertos y la aplicación piloto realizada, etapas que 
validaron la versión final del instrumento. Los objetivos de las preguntas 1, 2 y 7, cuyo análisis presentamos en este estudio, se detallan a continuación:

- Primera cuestión: "Las personas utilizan porcentajes. Piensa y escribe situaciones cotidianas en las que aparecen porcentajes. Nombra todas las que recuerdes".

Esta pregunta busca identificar las situaciones de uso común del porcentaje, lo cual permite analizar las respuestas en base al sentido como componente del significado. Se inicia contextualizando con una afirmación y por medio de ella se incita a evocar situaciones cotidianas en donde se use la noción de porcentaje. Su objetivo es recoger información que permita indagar en la tercera componente de la terna del significado, es decir, sus sentidos y modos de uso, detectando situaciones asociadas al uso de los porcentajes en la vida cotidiana.

- Segunda cuestión: “Veinticinco por ciento”, es una forma de expresar porcentajes. Representa en éste espacio otras formas que conozcas para mostrar ese mismo porcentaje.

El propio enunciado utiliza una forma verbal de representar un porcentaje, la pregunta se ha propuesto así para estimular y direccionar, en torno a un porcentaje específico, otras representaciones distintas que los estudiantes conozcan y recuerden. Se busca recoger una diversidad de sistemas de representación, que expresen un mismo porcentaje de distintos modos.

- Séptimo enunciado "Explica con tus propias palabras en qué consiste un tanto por ciento".

Pretende explorar conceptos básicos del "porcentaje" y las relaciones entre ellos, es decir, la referencia del concepto.

La versión final del cuestionario completo aplicado se encuentra en el Anexo E, el cual presenta la siguiente estructura: 
- Una página de presentación, donde se explica brevemente el propósito del instrumento además de instrucciones generales. También se recogen datos de identificación de cada estudiante como del colegio donde se aplica.

- La segunda parte consta de los ocho enunciados de respuesta abierta que responden a los propósitos antes descritos.

\subsection{Aplicación}

Se realizó una aplicación piloto donde se puso a prueba una primera versión del cuestionario. Se contó con la participación de 24 estudiantes, que cursan séptimo básico en Chile, que en el año anterior estudiaron de manera introductoria la noción de porcentaje y que en el año escolar en curso, no han estudiado nuevamente este contenido. La aplicación piloto permitió mejorar el cuestionario en la precisión del lenguaje empleado en los enunciados y el orden. Mayor detalle se registra en el Anexo D.

La aplicación del cuestionario diseñado para este estudio tuvo lugar el lunes 18 de abril del presente año. Se contó con la colaboración de tres encuestadores, quienes acudieron a cada establecimiento educacional con una carta (Anexo F) que explicaba el propósito del estudio, mediante la cual se solicitaba autorización para aplicar el instrumento. Los encuestadores contaban con un protocolo especialmente diseñado para orientar las acciones y pasos a seguir en el momento de la aplicación, el cual se puede consultar en el Anexo G.

En el momento de la aplicación el profesor a cargo del curso acompañó el proceso, mientras tanto el encuestador resguardó las condiciones necesarias para la recogida de datos. El tiempo de aplicación no fue limitado, y en promedio los estudiantes ocuparon 40 minutos para responder.

Una vez recogidos los cuestionarios, fueron remitidos a los investigadores para la organización de sus datos y el análisis de la información. 


\subsection{Organización de la información}

Para el análisis de los datos se seleccionaron los 100 cuestionarios de los estudiantes que habían respondido al menos a una de las preguntas. Cuando un estudiante sólo responde una de las ocho preguntas, se considera que dicho estudiante forma parte de la muestra, es decir, sus respuestas están dentro del total recogido para cada pregunta en particular. Uno de los valores de respuesta será "en blanco".

A continuación, se procedió a identificar cada uno los cuestionarios recogidos. Se trata de un código alfanumérico de cinco casillas; la primera es una letra mayúscula que se refiere al colegio en que se implementó el cuestionario (A, B o C), las dos siguientes indican el curso, en nuestro caso el número 7 de séptimo año, seguido de una letra minúscula señalando si se trata del curso "a" o "b", finalmente en las últimas dos casillas se indica el orden numérico asignado a cada estudiante con la consideración que previamente se han ordenado alfabéticamente según sus apellidos.

Con el propósito de organizar la información recogida para su posterior análisis, se procedió a transcribir todas las respuestas en una tabla de doble entrada, en una hoja de cálculo Excel. La tabla se estructura de la siguiente forma:

- En la primera columna se enumeran los cuestionarios.

- En la segunda columna, se indica el código alfanumérico asignado al cuestionario de cada estudiante.

- En la siguientes ocho columnas, se registra la transcripción de todas las respuestas proporcionadas a cada pregunta del cuestionario.

$\mathrm{Al}$ realizar la lectura por filas, se pueden apreciar las respuestas que cada estudiante ha registrado a cada reactivo del instrumento. En el caso de aquellos enunciados referidos a una representación, por ejemplo la pregunta 2 , se han descrito detalladamente y para el análisis se revisan nuevamente los cuestionarios. Cuando un estudiante propone más de una forma de representación, sus aportes se registran en cada variante posible que surja. La similitud entre algunas de las respuestas permite que surjan temas, en ellos es posible agrupar las ideas expresadas por los estudiantes. 


\subsection{Análisis de los datos}

En este estudio, se buscó determinar la variabilidad de respuestas por pregunta y pretendemos identificar e interpretar qué componentes del significado se detectan en la información que los estudiantes han proporcionado. En el análisis no se consideraron respuestas correctas o incorrectas.

Se establecieron dos bloques de análisis, el primero lo integran los enunciados 1, 2, 3 y 7 , referidos a las componentes del significado del concepto matemático de porcentaje. El segundo bloque incluye los enunciados 4, 5, 6 y 8, referidos a situaciones problemas que involucran porcentajes. Debido al tiempo disponible para la realización de este trabajo fin de máster, concentramos el análisis de las respuestas recogidas a las preguntas 1, 2 y 7 ya que cada una de ellas está orientada a una componente distinta de la terna semántica que seguimos en este estudio. En los Anexos H, I y J, se pueden consultar las respuestas recogidas de los estudiantes a cada pregunta respectivamente.

Dado que las preguntas del cuestionario admiten respuestas que no son univocas, es decir, un mismo alumno puede expresar una o varias ideas diferentes, por ello se procedió a la revisión de datos de cada pregunta en particular. La similitud entre algunas de las respuestas permitió que surgiesen temas, en ellos es posible agrupar las ideas expresadas por los estudiantes.

El análisis se realizó en base a las tres componentes del significado de un concepto de las matemáticas escolares, es decir, buscamos indicios de los sistemas de representación empleados, de la estructura matemática que se pone en evidencia y finalmente, de los sentidos y modos de uso en que los estudiantes emplean la noción de porcentaje.

\subsection{Fiabilidad y validez}

Cada pregunta del cuestionario se diseñó en función de las tres componentes del significado de un concepto matemático escolar, bajo la terna representación-estructura conceptual-sentido, buscando que los enunciados tuviesen una redacción clara, sencilla, libre de distractores y que respondiesen a los objetivos planteados para cada uno de ellos. 
El instrumento se ha sometido a un proceso de validación realizado en dos modalidades simultáneas. Por un lado, se ha consultado a cuatro expertos, profesores investigadores que previamente han trabajado en elaboración de cuestionarios semánticos para otros conceptos matemáticos. En paralelo, se realizó una aplicación piloto a 24 estudiantes, que cursan séptimo año de educación básica en Chile, que en el año anterior estudiaron de manera introductoria la noción de porcentaje y que en el año escolar en curso, no han trabajado nuevamente este contenido.

Los aportes y consideraciones relevantes para la mejora del cuestionario se detallan en el Anexo D, a partir de las cuales se construyó la versión final del instrumento. 


\section{CAPÍTULO 4: ANÁLISIS DE LOS DATOS}

En este capítulo se presenta el análisis de los datos de las respuestas dadas por los 108 estudiantes que cursan séptimo año básico en Chile. Del total de participantes, 8 estudiantes no han respondido a ninguna pregunta por lo que no se consideraron participantes del estudio y fueron excluidos del análisis realizado.

En promedio, los participantes respondieron a seis de las ocho preguntas planteadas en torno al concepto de porcentaje. La tabla 4 detalla la cantidad de respuestas obtenidas para cada una de las preguntas del cuestionario aplicado.

Tabla 4. Respuestas obtenidas en cada pregunta

\begin{tabular}{|c|c|}
\hline Número de pregunta & Frecuencia \\
\hline 1 & 89 \\
\hline 2 & 88 \\
\hline 3 & 78 \\
\hline 4 & 90 \\
\hline 5 & 66 \\
\hline 6 & 75 \\
\hline 7 & 63 \\
\hline 8 & 48 \\
\hline Total & 597 \\
\hline
\end{tabular}

En los siguientes apartados presentamos el análisis de las respuestas a las preguntas 1, 2 y 7 del primer bloque, realizado en base a las tres componentes del significado de un concepto matemático.

\subsection{Análisis de las respuestas a la pregunta 1}

El enunciado de la primera pregunta del cuestionario es "Las personas utilizan porcentajes. Piensa y escribe situaciones cotidianas en las que aparecen porcentajes. Nombra todas las que recuerdes." 
Esta pregunta se ha planteado con el fin de detectar los sentidos y modos de uso, es decir, términos, situaciones y contextos asociados al uso de los porcentajes en la vida cotidiana, sin embargo esto no excluye que se manifiesten otras componentes de la terna semántica.

Además, cabe destacar que esta pregunta admite múltiples respuestas, es decir, un estudiante puede señalar más de una situación en la que se utilicen porcentajes, hecho que hemos detectado en los datos recogidos. Por ello, al ejemplificar, sólo se tomarán aquellas secciones de las respuestas referidas a cada categoría en particular.

La tabla 5 muestra la primera revisión de los datos de la pregunta 1, donde se realizó una primera agrupación de las respuestas en temas que surgen de la similitud que detectamos y se evidencia la variabilidad de respuestas posibles.

Tabla 5. Respuestas distintas a la pregunta 1

Temas detectados en las respuestas

Frecuencia

1. En descuentos, ofertas y rebajas 68

2. Señalando los lugares donde se utiliza

3. Como resultado de la medida en que no se indica el valor total

4. Disminuir o bajar un determinado porcentaje 5

5. En encuestas 5

6. En tareas y problemas

7. Para indicar porcentaje de asistencia

8. Situaciones personales de asistencia a un lugar o al compartir

9. En gráficos

10. En la composición de una sustancia

11. Como expresión de la cantidad de algo

12. En los productos

13. Sólo escriben porcentajes aislados

14. En matemática

15. Al repartir

16. Para expresar totalidad

17. Ventas

18. Cuentas (recibos)

19. Para indicar porcentaje de llenar algo

20. Aumento o algo con "cantidad extra"

21. En cambios de sueldo

22. Para indicar la carga del celular

23. Deudas 


\begin{tabular}{lc}
\hline \multicolumn{1}{c}{ Temas detectados en las respuestas } & Frecuencia \\
\hline 24. En tablas & 1 \\
25. En las votaciones & 1 \\
26. Al consumir & 1 \\
27. Al indicar probabilidad & 1 \\
28. Los médicos & 1 \\
29. Como porcentaje de algo & 1 \\
30. Muestra tabla en la que calculan porcentajes & 1 \\
31. En blanco & 11 \\
Total & 180 \\
\hline
\end{tabular}

A partir de los grupos de respuestas anteriores, hemos organizado los datos de esta pregunta en base a las categorías de situaciones personales, educativas o laborales, públicas y científicas del proyecto PISA (OCDE, 2005). Se añade un apartado en el que agrupamos aquellas respuestas que por su naturaleza no responden a ninguna de las situaciones anteriores.

\section{a) Situaciones personales}

Son aquellas relativas a circunstancias propias de la vida cotidiana en el ámbito personal y/o familiar. Están directamente relacionadas con las actividades diarias de los alumnos. En la tabla 6 se detallan las situaciones personales identificadas en las respuestas del alumnado.

Tabla 6. Situaciones personales identificadas en las respuestas a la pregunta 1

\begin{tabular}{lc}
\hline \multicolumn{1}{c}{ Tipos de situaciones personales } & Frecuencia \\
\hline Disminución & 5 \\
Expresiones verbales & 5 \\
Repartir & 3 \\
Como expresión de totalidad & 3 \\
Llenar & 2 \\
Cargar el teléfono celular & 2 \\
Cuentas (recibos, facturas) & 2 \\
Aumento & 2 \\
Deudas & 1 \\
Consumir & 1 \\
Indicador de probabilidad & 1 \\
Total & 27 \\
\hline
\end{tabular}


Ejemplos de estos tipos de situaciones encontramos en la respuesta del alumno B7a11, "La batería de mi celular tenía un $26 \%$ de batería y ahora tiene un $16 \%$ " y de B7b13, "Cuando uno invita a su cumpleaños harta gente pero no va toda, va la mitad o menos de la mitad como el 30\% de los invitados van y la mitad seria el 50\%" ejemplifican este tipo de situaciones. En ellas, los estudiantes manifiestan momentos cotidianos en que utilizan expresiones que incluyen el porcentaje.

\section{b) Situaciones educativas o laborales}

Estas respuestas hacen alusión a situaciones propias de las matemáticas escolares como tareas y problemas. Se producen en la vida del alumno en el centro escolar o en un entorno de trabajo. La tabla 7 detalla los tipos de situaciones educativas y laborales identificadas.

Tabla 7. Situaciones educativas o laborales identificadas en las respuestas a la pregunta 1

\begin{tabular}{lc}
\hline \multicolumn{1}{c}{ Tipos de situaciones educativas o laborales } & Frecuencia \\
\hline Descuento, ofertas y rebajas & 68 \\
Lugares comerciales & 22 \\
Tareas y problemas escolares & 8 \\
Porcentajes de asistencia & 5 \\
Productos & 4 \\
Sueldos & 2 \\
Venta & 2 \\
Calculo de porcentaje en una tabla & 1 \\
Total & 112 \\
\hline
\end{tabular}

Ejemplos de este tipo de situaciones son:

- "El 20\% de las niñas no hizo la tarea" (B7a08)

- "En los supermercados cuando hay descuentos. En las tiendas de ropa en descuento" (B7a07)

- "El porcentaje de venta. Porcentaje de descuento" (B7a13)

- "En tiendas, almacenes o supermercados (descuento)" (B7b04)

En estos ejemplos de respuesta se evidencia claramente situaciones del ámbito escolar o laboral, ya que incluyen términos relativos al centro escolar o comercial. 


\section{c) Situaciones públicas}

En este caso, se incluyen aquellas situaciones relacionadas con la comunidad local $\mathrm{u}$ otra más amplia. Se trata de situaciones que se encuadran en torno a la forma en que los estudiantes entienden las relaciones entre los elementos del entorno público. La tabla 8 detalla este tipo de situaciones.

Tabla 8. Situaciones públicas identificadas en las respuestas a la pregunta 1

\begin{tabular}{lc}
\hline \multicolumn{1}{c}{ Tipos de situaciones públicas } & Frecuencia \\
\hline Resultados de la medida & 6 \\
Encuestas & 5 \\
Gráficos & 4 \\
Porcentaje como expresión de cantidad & 4 \\
Tablas & 1 \\
Votaciones & 1 \\
Total & 21 \\
\hline
\end{tabular}

Los estudiantes manifiestan reconocer el uso de porcentajes como resultado de la medida, en las encuestas, cuando se comunican resultados estadísticos mediante gráficos, en la publicidad, tal como se evidencia en los siguientes ejemplos de respuestas:

- "El 60\% de los niños juega al PC, el 80\% viviría en el campo, los gatos duermen un $70 \%$ de su vida" $(\mathrm{A} 7 \mathrm{a} 01)$

- "En los comerciales, cuando sale por ejemplo: el 50\% de las personas usa tal producto" (A7a17)

\section{d) Situaciones científicas}

Esta categoría abarca el uso del porcentaje en situaciones del quehacer científico. Las situaciones presentan mayor grado de abstracción y pueden implicar la comprensión de un proceso tecnológico, una situación teórica o una tarea problema explícitamente matemática. La tabla 9 ejemplifica este tipo de situaciones. 
Tabla 9. Situaciones científicas identificadas en las respuestas a la pregunta 1

\begin{tabular}{lc}
\hline \multicolumn{1}{c}{ Tipo de situaciones científicas } & Frecuencia \\
\hline Como composición de una sustancia & 4 \\
Médicas & 1 \\
Total & 5 \\
\hline
\end{tabular}

Las situaciones de carácter científico tienen la cualidad de ser más abstractas y específicas como el lenguaje propio de los médicos, que se muestra en los ejemplos de respuestas que siguen:

- "Cuando los médicos dicen: tiene un cincuenta porciento de capacidad intelectual" (B7a19)

- "Composición de una mezcla (20\% de agua...)" (B7a05)

\section{e) Otras respuestas de los estudiantes}

Por último, esta categoría incluye aquellas ideas expresadas por los estudiantes en sus respuestas a la primera pregunta, que no responden a las clasificaciones anteriores y que se presentan de manera singular o con menor frecuencia, tal como se muestran en la tabla 10.

Tabla 10. Otras situaciones identificadas en las respuestas a la pregunta 1

\begin{tabular}{lc}
\hline \multicolumn{1}{c}{ Otro tipo de situaciones } & Frecuencia \\
\hline Porcentajes aislados & 4 \\
En blanco & 11 \\
Total & 15 \\
\hline
\end{tabular}

Un ejemplo de este tipo de situaciones lo presentamos a través de la figura 5.

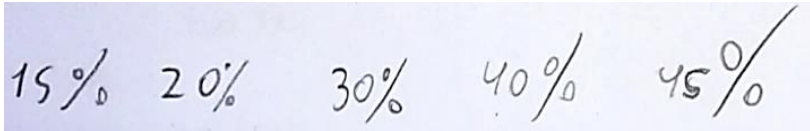

Figura 5. Respuesta de C7a20 a la pregunta 1 
Se aprecia que el estudiante sólo utiliza la notación tradicional del porcentaje, pero no menciona ninguna situación en particular.

Revisando los datos por alumno, se identifica que 51 estudiantes dan ejemplos de uso del porcentaje que se pueden clasificar al menos en un tipo de situaciones, 24 estudiantes ejemplifican con al menos dos tipos de situaciones diferentes y 6 estudiantes dan ejemplos que pueden clasificar hasta en tres tipos de situaciones. A continuación se presentan algunos ejemplos de respuestas recibidas en que se reconocen varios tipos de situaciones.

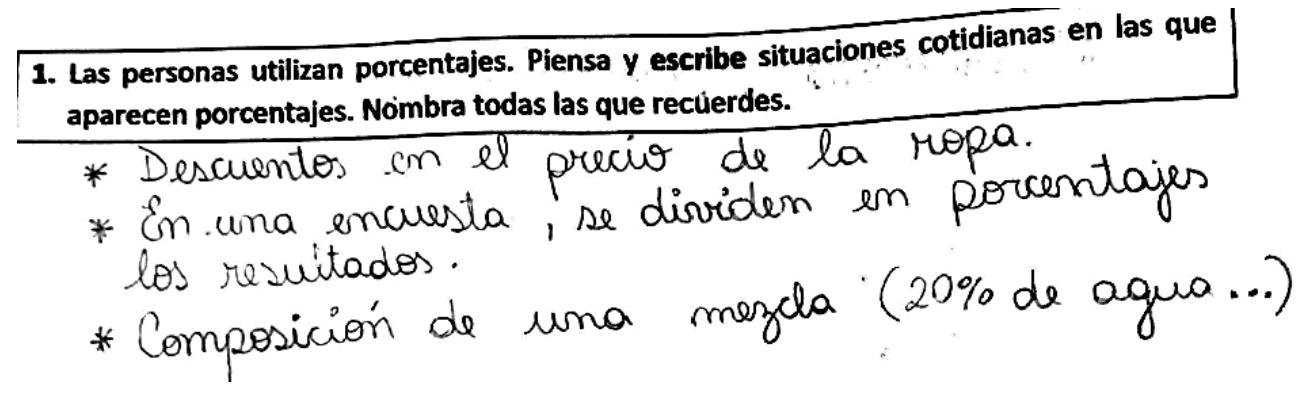

Figura 6. Respuesta de B7a05 a la pregunta 1

En la figura 6, identificamos situaciones del ámbito comercial, destacando la idea del descuento, situaciones públicas referidas a encuestas y comunicación de sus resultados, ya que interpretamos que al decir "se dividen en porcentajes los resultados", entendemos que alude a la comunicación de los resultados mediante la utilización de porcentajes, en una gráfica o tal vez en una tabla, ya que no lo explicita. Finalmente, las situaciones científicas se manifiestan en la tercera opción que escribe, cuando se utilizan los porcentajes para referirse a la composición de una mezcla que casi siempre se expresan en porcentajes.

En la figura 7 destaca nuevamente el descuento como la primera idea que aflora al pensar en usos del porcentaje.

$$
\begin{aligned}
& \text { 1. Las personas utilizan porcentajes. Piensa y escribe situaciones cotidanas en las que } \\
& \text { aparecen porcentajes. Nombra todas las que recuerdes. }
\end{aligned}
$$

Figura 7. Respuesta de B7a06 a la pregunta 1 
Se manifiesta también la idea de comunicar en forma porcentual una parte de una magnitud total que no se explicita. En esta situación, como mencionan Gairín y Sancho (2002, p. 161), el porcentaje conlleva la comparación de resultados de la medida de dos cantidades de magnitud, la medida de una parte de la cantidad de magnitud total que se considera y la medida de la totalidad de dicha cantidad de magnitud (caso en el que el porcentaje debe ser menor o igual a 100).

Resaltamos el uso del $100 \%$ como expresión de totalidad que se utiliza comúnmente en el lenguaje cotidiano, además de otras expresiones asociadas a la probabilidad de ocurrencia de un evento.

\subsubsection{Análisis a la pregunta 1 desde las componentes de la terna semántica}

Un segundo análisis de las respuestas obtenidas en la primera pregunta, se realizó en base a las componentes del significado. Debido a que la cuestión está planteada con el fin de identificar sentidos y modos de uso de la noción de porcentaje, en éste segundo análisis buscamos detectar cómo se manifiestan las otras dos componentes del significado, es decir, los sistemas de representación y la estructura conceptual.

Con respecto a la componente de sistemas de representación, se identifican las representaciones que se detallan en la tabla 11.

Tabla 11. Sistemas de representación identificados en la pregunta 1

\begin{tabular}{lc}
\hline \multicolumn{1}{c}{ Representaciones } & Frecuencia \\
\hline Notación de porcentaje & 42 \\
Gráfica estadística circular & 2 \\
Numérico-verbal & 1 \\
Tabla & 1 \\
Verbal & 1 \\
Total & 47 \\
\hline
\end{tabular}

De los 89 estudiantes que respondieron a esta pregunta, 46 utilizaron alguna representación del porcentaje, el resto sólo enunció situaciones sin manifestar 
explícitamente el porcentaje por medio de alguna de sus representaciones. Sólo un estudiante utiliza dos tipos de sistemas de representación, la notación tradicional del porcentaje y una representación gráfica que podemos clasificar como gráfico estadístico circular, que se contabilizaron de manera independientes lo cual explica la frecuencia de 47. La figura 8 muestra la respuesta del estudiante que empleo dos sistemas de representación.

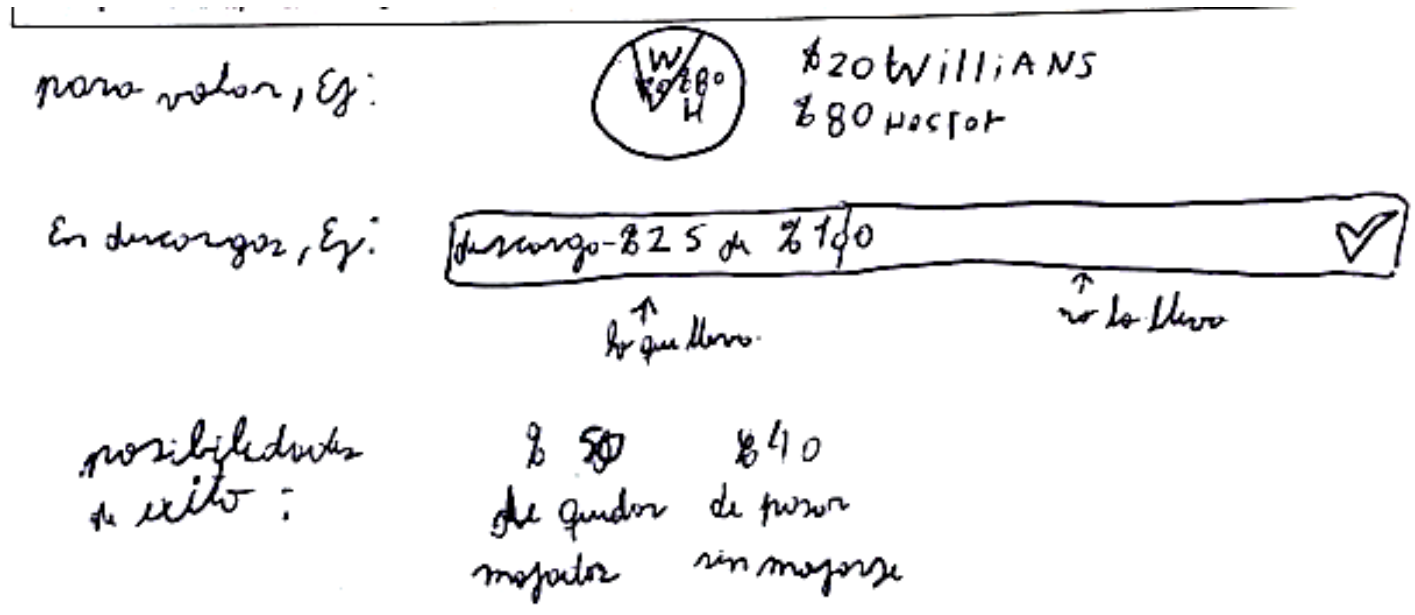

Figura 8. Respuesta de A7a25 a la pregunta 1

En el ejemplo anterior, se identifica que, curiosamente, este estudiante utiliza el símbolo del porcentaje ubicándolo antes del numeral. Distingue las votaciones como situaciones de uso del porcentaje y ejemplifica con un gráfico circular asignando 80 y $20 \%$ respectivamente. Además, en las situaciones de cargar o descargar, acompaña con una barra rectangular en la que añade que $25 \%$ de $100 \%$ es lo que lleva de carga. En la mayoría de las respuestas se utiliza la notación tradicional del porcentaje. Detectamos que un estudiante añade lo que parece ser un signo negativo delante del numeral cuando se refiere a la idea de descuento (figura 9), es decir, vincula las ideas de porcentaje y descuento con el signo negativo.

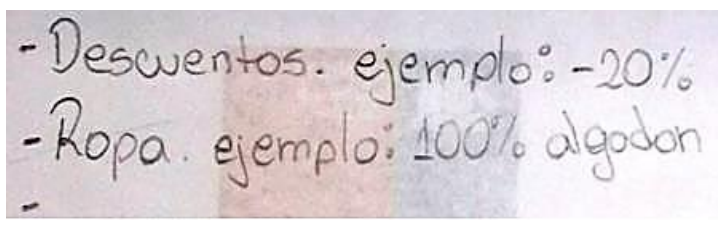

Figura 9. Respuesta del alumno B7b02 a la pregunta 1 
Respecto a la estructura conceptual, de los 89 estudiantes que respondieron a esta pregunta, identificamos 8 respuestas que involucran la relación parte-todo, la relación parte-parte y el porcentaje como un operador con el detalle de frecuencias que se indican en la tabla 12 .

Tabla 12. Elementos de la estructura conceptual identificados en la pregunta 1

\begin{tabular}{lc}
\hline \multicolumn{1}{c}{ Tipo de estructura } & Frecuencia \\
\hline Relación parte-todo aditiva & 2 \\
Por ciento como resultado de la medida & 2 \\
Operador & 2 \\
Relación de cambio (disminución) & 1 \\
Total & 7 \\
\hline
\end{tabular}

Los 82 estudiantes restantes, no manifiestan en sus respuestas a la primera pregunta componentes de la estructura conceptual de porcentaje, sólo aluden directamente a situaciones de uso.

En la primera pregunta, que recoge información sobre las situaciones de uso del porcentaje, el alumno A7a03 responde "Ejemplo: en una escuela hay 100 alumnos y 65 alumnos tienen promedios sobre 5,0 ¿qué porcentaje se puede representar este caso? R: $65 \%$. En términos de la estructura conceptual, esta respuesta evidencia una relación partetodo. El todo lo representan los 100 alumnos de la escuela, de los cuales una parte, 65 de ellos, cumplen una determinada condición. También podría considerarse una relación proporcional propia de la estructura multiplicativa. Así, se pone en evidencia que el porcentaje puede adoptar distintos significados y se adapta a distintas estructuras o relaciones matemáticas.

La figura 10 muestra el uso del porcentaje como un operador de comparación multiplicativa, en el que sin mencionar situación alguna, organiza datos numéricos en una tabla y determina el $50 \%$ y el $25 \%$ de estos valores. 


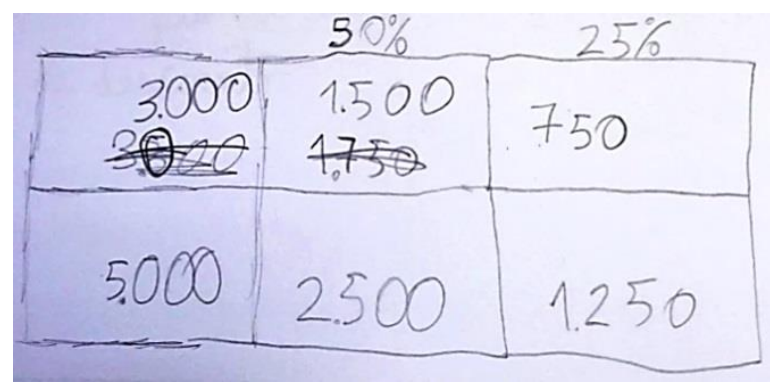

Figura 10. Respuesta de C7a23 a la pregunta 1

Como en la respuesta no hay cálculos por escrito, conjeturamos que el cálculo se realiza de manera mental y se asocia el $50 \%$ a la mitad y el $25 \%$ a la mitad de la mitad.

\subsubsection{Síntesis de la pregunta 1}

Como muestran los resultados obtenidos, resaltan por su amplia mayoría las situaciones educativas y laborales, siendo las laborales las de mayor frecuencia. Específicamente, el ámbito comercial es predominante en las respuestas sobre invención de situaciones que involucren porcentajes, hecho que concuerda con los fenómenos comerciales y mercantiles que se encuentran en los orígenes de esta noción. La tabla 13 sintetiza los resultados obtenidos para la primera pregunta en torno a los tipos de situaciones identificadas.

Tabla 13. Síntesis de resultados a la pregunta 1

\begin{tabular}{lcc}
\hline \multicolumn{1}{c}{ Tipos de situaciones } & Frecuencia & $\%$ \\
\hline Educativas o laborales & 112 & 62 \\
Personales & 27 & 15 \\
Públicas & 21 & 12 \\
Científicas & 5 & 3 \\
Otras & 4 & 2 \\
No contestan & 11 & 6 \\
Total & 180 & 100 \\
\hline
\end{tabular}

El término "descuento" y sus variaciones, destaca como término clave directamente relacionado con la noción de porcentaje, estrechamente vinculado con los lugares 
(establecimientos comerciales) en que frecuentemente se comunica información expresada mediante porcentajes.

Los estudiantes utilizan la representación convencional del porcentaje del numeral junto al símbolo “\%” y destaca la relación parte-todo como estructura conceptual que se manifiesta en las respuestas obtenidas para esta primera pregunta. De esta manera, a través del análisis realizado, identificamos indicios de las componentes de significado en las expresiones del alumnado en torno al concepto de porcentaje.

\subsection{Análisis de las respuestas a la pregunta 2}

En la segunda tarea del cuestionario el enunciado planteado como reactivo es: "Veinticinco por ciento", es una forma de expresar porcentajes. Representa en éste espacio otras formas que conozcas para mostrar ese mismo porcentaje.

En una primera revisión de las respuestas encontramos variados modos en que los participantes representan el porcentaje indicado. La tabla 14, presenta estas variantes junto a su frecuencia.

Tabla 14. Frecuencia de respuestas distintas a la pregunta 2

\begin{tabular}{|c|c|}
\hline Respuestas & Frecuencia \\
\hline $\begin{array}{l}\text { 1. Con notación de porcentaje, es decir, la tradicional combinación de } \\
\text { numeral y símbolo: "25\%" }\end{array}$ & 66 \\
\hline 2. Con notación de fracción decimal: " $25 / 100 "$ & 13 \\
\hline $\begin{array}{l}\text { 3. Utilizando combinaciones aditivas que resulten } 25 \text {, al que añaden el } \\
\text { símbolo } \% \text {. }\end{array}$ & 10 \\
\hline $\begin{array}{l}\text { 4. Mediante gráficas estadísticas circulares en que representan preferencias } \\
\text { personales señalando porcentajes. }\end{array}$ & 7 \\
\hline 5. En forma escrita & 7 \\
\hline $\begin{array}{l}\text { 6. Mediante representación gráfica de una relación parte todo, en la que el } \\
\text { todo es una superficie circular, dividida en partes iguales, una de las cuales } \\
\text { se colorea y/o señala como " } 25 \% \text { " }\end{array}$ & 3 \\
\hline $\begin{array}{l}\text { 7. Mediante representación gráfica de una relación parte todo, en la que el } \\
\text { todo es una figura geométrica cuadrada o rectangular que aparece dividida } \\
\text { en partes iguales, una de las cuales se colorea y/o señala como " } 25 \% "\end{array}$ & 3 \\
\hline 8. Por medio de cuadricula $10 \times 10$ en donde colorean 25 cuadritos & 3 \\
\hline $\begin{array}{l}\text { 9. Con relaciones multiplicativas y aditivo-multiplicativas que resulten } 25 \text {, } \\
\text { valor al que pueden añadir o no el símbolo } \% \text {. }\end{array}$ & 3 \\
\hline
\end{tabular}




\begin{tabular}{|c|c|c|}
\hline \multicolumn{2}{|r|}{ Respuestas } & \multirow{2}{*}{$\frac{\text { Frecuencia }}{2}$} \\
\hline 10. & Con notación fraccionaria: " $1 / 4 "$ & \\
\hline 11. & Con notación decimal: “0,25” & 2 \\
\hline 12. & Mediante gráfico de barras en los que incorporan porcentajes & 2 \\
\hline \multicolumn{3}{|c|}{ solicitado. } \\
\hline 14. & $\begin{array}{l}\text { Con un porcentaje al que previamente añaden el signo menos (-), tal } \\
\text { to se muestra: "- }-25 \% "\end{array}$ & 1 \\
\hline \multicolumn{2}{|r|}{$\begin{array}{l}\text { como se muestra: “- } 25 \% ” \\
\text { 15. Como razón en la expresión: " } 25: 100 "\end{array}$} & 1 \\
\hline 16. & Con la expresión fraccionaria " $2 / 5$ " & 1 \\
\hline \multicolumn{2}{|r|}{$\begin{array}{l}\text { 17. Indicando operaciones aritméticas al escribir: "en suma, resta, } \\
\text { división, multiplicación y expresiones algebraicas". }\end{array}$} & 1 \\
\hline 18. & Como consideración unitaria de cada número y símbolo: “2 y 5 y \%” & 1 \\
\hline 19. & Mediante la expresión “25,50\%” & 1 \\
\hline 20. & Mediante la expresión: "1000:4” & 1 \\
\hline 21. & Por medio de combinación numérico-verbal tal como: "25 por ciento" & 1 \\
\hline 22. & Mediante la lectura de razón en la forma: "25 es a 100” & 1 \\
\hline 23. & Escriben: “25*100” & 1 \\
\hline 24. & Escribiendo: "en gráficos” & 1 \\
\hline 25. & Con la expresión: "es 100:25” & 1 \\
\hline 26. & Escribiendo: “25 a 7” & 1 \\
\hline 27. & No Contesta & 12 \\
\hline Tot & & 147 \\
\hline
\end{tabular}

Cuando un estudiante propone más de una forma de representación, sus aportes se registran en cada variante posible que surja. De esta forma, detectamos que 2 estudiantes muestran cuatro formas de representación, 7 de ellos utilizan tres representaciones, 28 estudiantes muestran dos y finalmente 62 estudiantes emplean al menos un modo de representación del porcentaje.

Tras la primera revisión de los datos y debido a la semejanza encontrada en algunas de las respuestas, surgen temas que permiten agrupar las diferentes representaciones proporcionadas por los estudiantes. De los temas surgen conceptos claves útiles para agrupar las respuestas en subcategorías. 


\section{a) Representaciones gráficas}

Dentro de esta categoría, se recogen diagramas continuos de área. Entendemos como diagramas continúo de área aquellas representación gráfica de una relación partetodo, en la que el todo es una figura geométrica regular sencilla (superficies circulares, cuadradas o rectangulares), que aparece dividida en partes, una de las cuales se colorea y/o señala como $25 \%$. También se incluye la cuadricula de 10x10, que consiste en una región cuadrada, dividida en cien cuadritos de los cuales se colorean los que indica un determinado porcentaje. Se asocia también a una forma de representación de los números decimales. El detalle se presenta en la tabla 15.

Tabla 15. Variantes de representación gráfica

\begin{tabular}{lc}
\hline \multicolumn{1}{c}{ Tipos de representaciones gráficas } & Frecuencia \\
\hline Circulares & 3 \\
Rectangulares & 3 \\
Cuadrícula de 10x10 & 3 \\
Total & 9 \\
\hline
\end{tabular}

A continuación se presentan ejemplos de respuestas que los estudiantes han dado para la pregunta 2 .

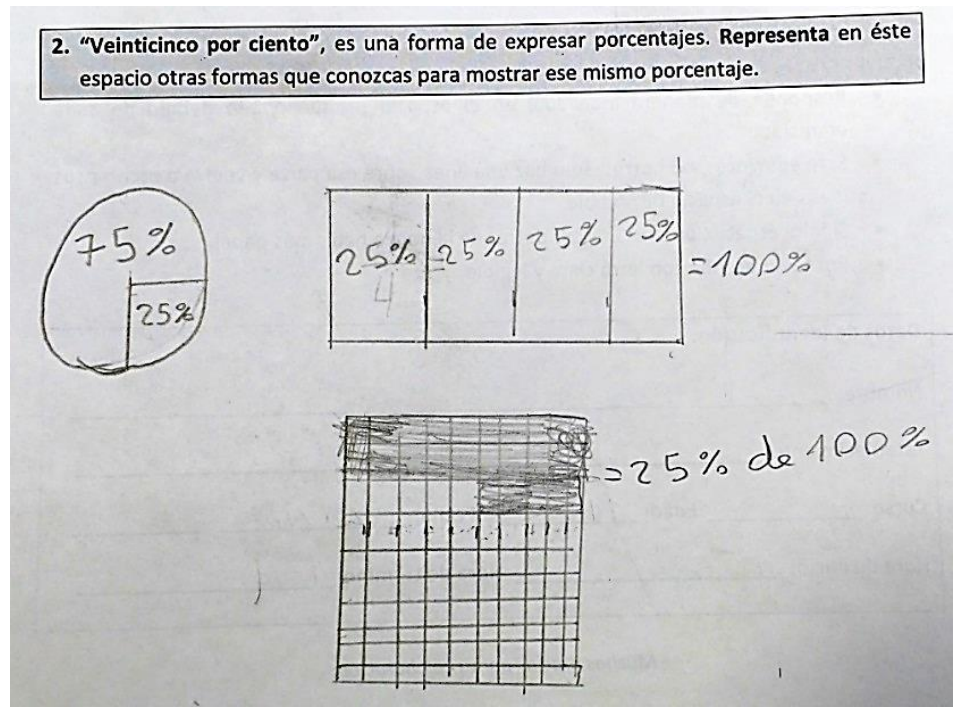

Figura 11. Respuesta del alumno A7a15 a la pregunta 2 
La figura 11, muestra dos ejemplos de los diagramas de área, por un lado la cuadricula 10x10, muy utilizada en la representación gráfica de los números decimales, que gracias a su particular subdivisión en cien partes iguales, permite representar porcentajes reforzando su interpretación como expresión fraccionaria (25/100) y a su vez como expresión decimal $(0,25)$. Este particular modo de representación logra posicionar al porcentaje como una forma de representar fracciones o decimales mediante una notación que no implica ni la raya fraccionaria o la coma decimal respectivamente.

Destacamos la región rectangular, claramente dividida en cuatro partes iguales, cada una de las cuales se señala con el $25 \%$, lo que deja ver la equivalencia con la fracción 1/4. Es también una representación de la relación parte-todo, ya que la región rectangular se ha dividido en cuatro partes iguales. Del mismo modo, el diagrama circular presentado nos lleva a reflexionar y considerar la necesidad de aclarar la diferencia entre un diagrama de área circular y una gráfica estadística también circular.

Consideramos un diagrama de área a la figura regular (circular, cuadrada, rectangular, etc.) que se divide en partes iguales, de las cuales se toma una parte que, en nuestro caso, represente un determinado porcentaje.

Otro tipo de representación gráfica son los gráficos estadísticos, circulares o de barra, en la que indican preferencias personales asociadas a un determinado porcentaje. En cuanto al gráfico estadístico circular (diagrama de sectores), se caracteriza por repartir el círculo de manera proporcional a las partes que se desean representar, no siendo necesario que estas sean de igual tamaño. El diagrama de sectores es muy utilizado para comunicar información en forma porcentual en los medios de comunicación. La tabla 16 detalla la frecuencia en que se presentan.

Tabla 16. Variantes de representación con gráficas estadísticas

\begin{tabular}{lc}
\hline \multicolumn{1}{c}{ Tipo } & Frecuencia \\
\hline Circulares & 7 \\
De barra & 2 \\
Total & 9 \\
\hline
\end{tabular}


La figura 12 muestra un ejemplo de representación del porcentaje $25 \%$ mediante la utilización de graficas estadísticas.

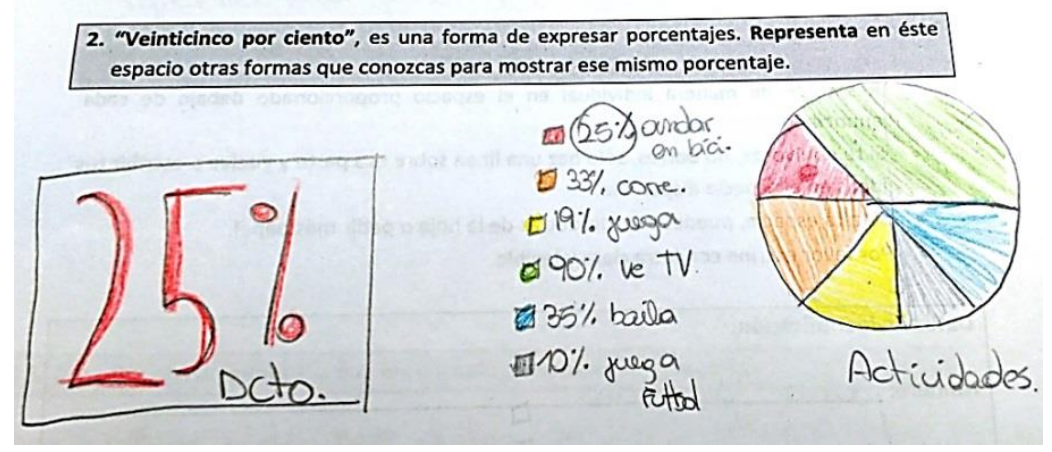

Figura 12. Respuesta de A7a09 a la pregunta 2

Aunque con errores en la sumatoria de porcentajes que representa, la respuesta de la figura 12, ejemplifica una gráfica estadística circular, cuyos sectores son proporcionales a las variables que representan, las cuales además son claramente identificables por los colores utilizados. Recalcamos que no es nuestro interés clasificar entre respuestas acertadas y erróneas, sino más bien, indagar en las representaciones que los estudiantes vinculan con la noción de porcentaje.

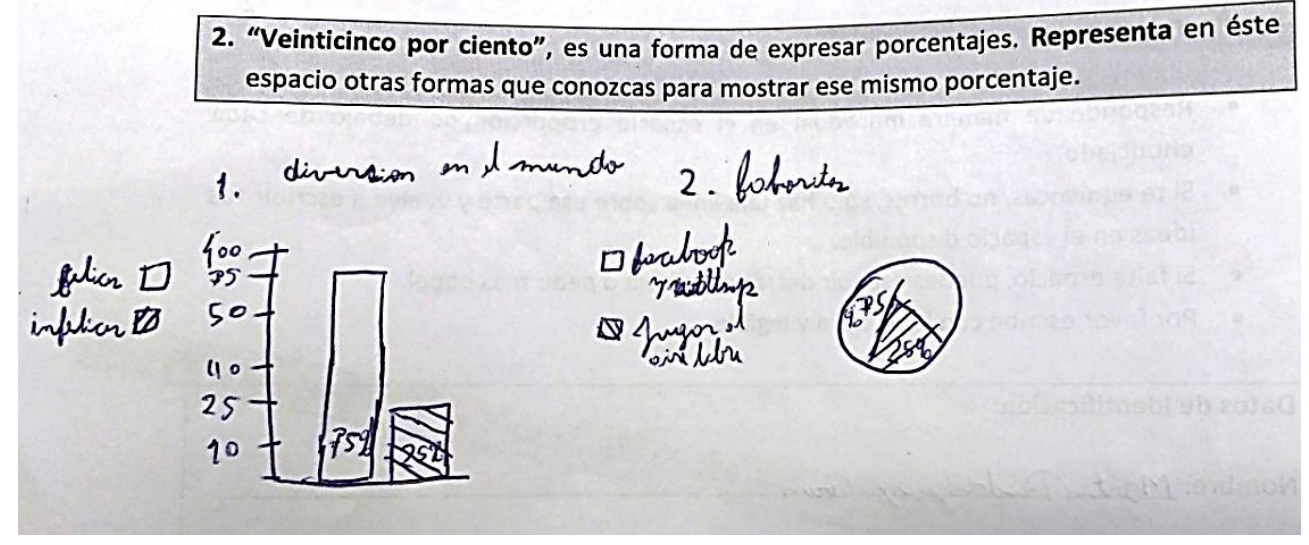

Figura 13. Respuesta de A7a25 a la pregunta 2

La figura 13, muestra la utilización de dos representaciones gráficas, por un lado el grafico de barras asociados a un porcentaje determinado (75 y $25 \%$ respectivamente) y su equivalente en la representación del diagrama de sectores circular. Ambo están asociados a una simbología que se detalla junto al gráfico. 


\section{b) Representaciones numérico-simbólicas}

En esta categoría identificamos la representación tradicional del porcentaje que emplean un numeral y el símbolo "\%". La tabla 17 detalla la frecuencia con que se presenta.

Tabla 17. Variantes de representación numérico-simbólica

\begin{tabular}{lc}
\hline Tipo & Frecuencia \\
\hline $25 \%$ & 66 \\
Otros porcentajes & 2 \\
Total & 68 \\
\hline
\end{tabular}

La figura 14 da cuenta de un ejemplo de uso de la notación tradicional del porcentaje.

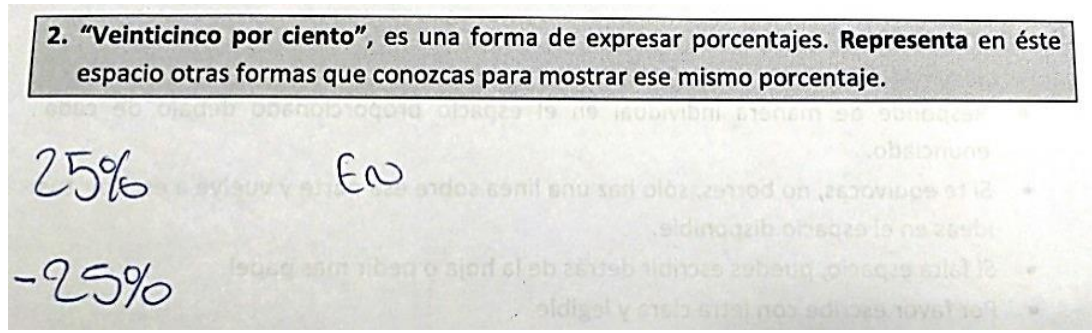

Figura 14. Respuesta de $\mathrm{A} 7 \mathrm{a} 02$ a la pregunta 2

Destacamos el ejemplo anterior ya que además de emplear la notación tradicional del porcentaje, el estudiante añade una forma alternativa que incluye lo que parece ser un signo negativo.

En la tabla 18, identificamos expresiones con notación fraccionaria del porcentaje señalado junto a su frecuencia. Se incluyen también aquellas que no se refieren directamente al porcentaje indicado en el enunciado de la pregunta 2, pero que muestran una fracción como modo de representación. 
Tabla 18. Variantes de repuesta con notación fraccionaria

\begin{tabular}{lc}
\hline Tipo & Frecuencia \\
\hline $25 / 100$ & 13 \\
Otras fracciones & 4 \\
Total & 17 \\
\hline
\end{tabular}

En la figura 15, se presenta un ejemplo de respuesta que evidencia que un mismo estudiante muestra varios modos de representar el 25\%. Enfatizamos la forma fraccionaria asociada a la notación tradicional del porcentaje y al diagrama que da cuenta de una relación parte-todo con el circulo dividido en cuatro partes iguales, cada una de ellas señalada con el $25 \%$.

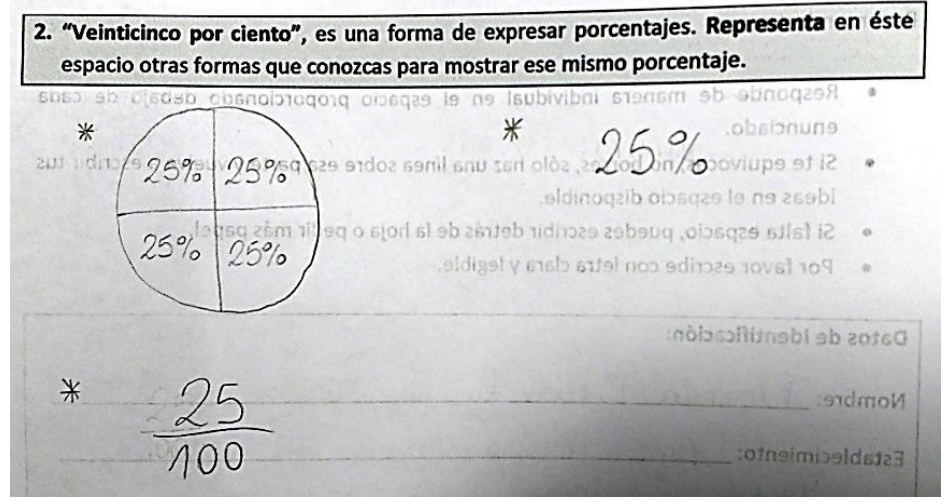

Figura 15. Respuesta de B7a05 a la pregunta 2

Identificamos representaciones del porcentaje mediante notación decimal, sean estas correspondientes al veinticinco por ciento solicitado en el enunciado de la pregunta 2 o no, que se detallan en la tabla 19.

Tabla 19. Variantes de representación con notación decimal

\begin{tabular}{lc}
\hline \multicolumn{1}{c}{ Tipo } & Frecuencia \\
\hline 0,25 & 2 \\
Otros decimales & 1 \\
Total & 3 \\
\hline
\end{tabular}

En la figura 16, se puede visualizar la división que se utiliza para cambiar de notación porcentual a la expresión decimal equivalente. Esto es reflejo de la riqueza que 
proporcionan las variadas formas representar un porcentaje, las equivalencias entre ellos y la pertinencia de su empleo en distintas situaciones.

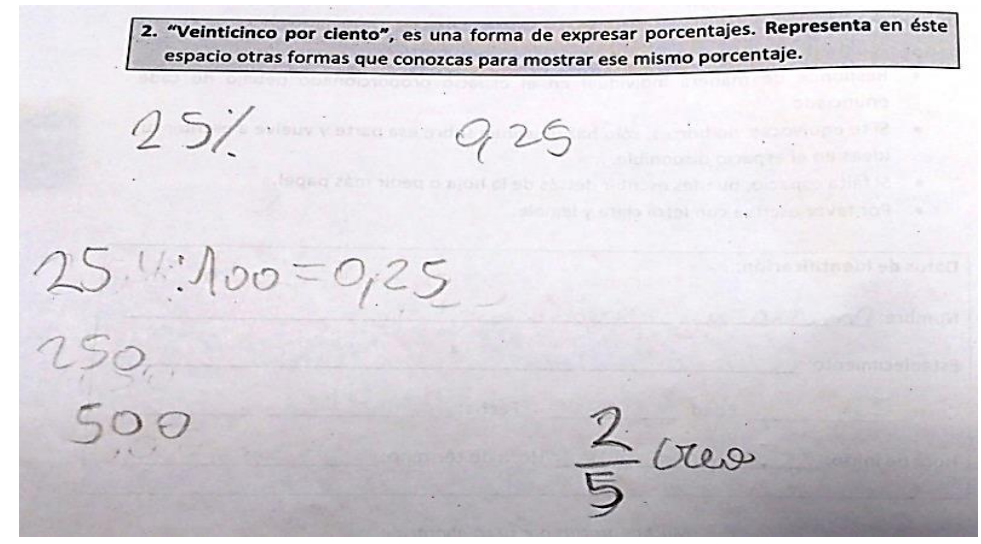

Figura 16. Respuesta de A7a14 a la pregunta 2

En general, se contemplan las representaciones del porcentaje como una razón en la forma $a: b$ de modo numérico verbal o bien la combinación numérico-verbal que se muestran en la tabla 20.

Tabla 20. Variantes de respuestas con notación de razón

\begin{tabular}{lc}
\hline \multicolumn{1}{c}{ Tipo } & Frecuencia \\
\hline $25: 100$ & 1 \\
"25 es a $100 "$ & 1 \\
Otros razones & 3 \\
Total & 5 \\
\hline
\end{tabular}

En la figura 17 se presenta un ejemplo de representación del porcentaje como razón junto a otros modos de expresar el veinticinco por ciento solicitado.

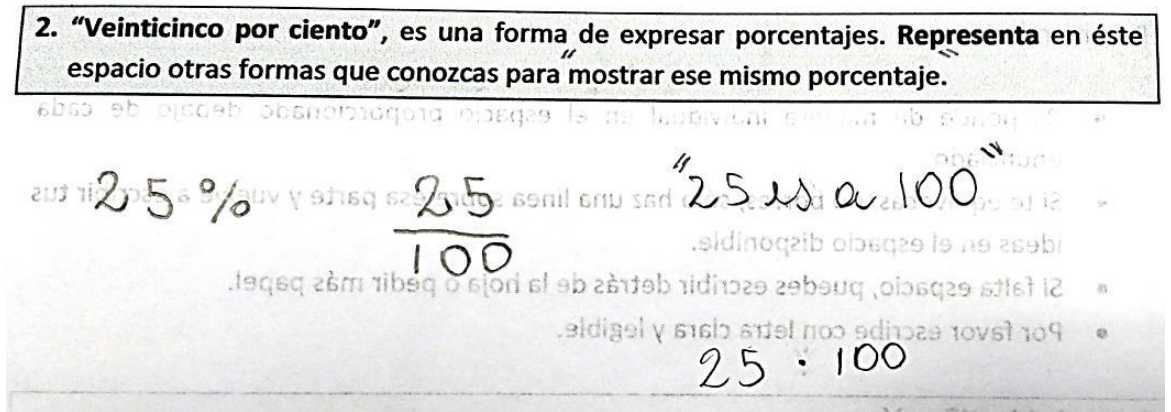

Figura 17. Respuesta de B7a06 a la pregunta 2 


\section{c) Representaciones verbales}

Entre las respuestas a la segunda pregunta, identificamos las representaciones verbales relativas al modo en el que se expresa verbalmente el porcentaje. También se contempla la variante que combina una parte numérica y otra verbal en el modo de referirse a un porcentaje determinado. El detalle de frecuencias se presenta en la tabla 21.

Tabla 21. Variantes de representación numérico - verbal

\begin{tabular}{lc}
\hline \multicolumn{1}{c}{ Tipo } & Frecuencia \\
\hline Verbal & 7 \\
Numérico - verbal & 1 \\
Total & 8 \\
\hline
\end{tabular}

Las figuras 18 y 19 muestran ejemplos de respuestas en que se utiliza la combinación numérica-verbal y una expresión verbal respectivamente.

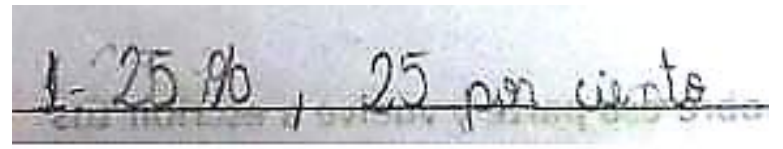

Figura 18. Respuesta de $\mathrm{B} 7 \mathrm{a} 02$ a la pregunta 2

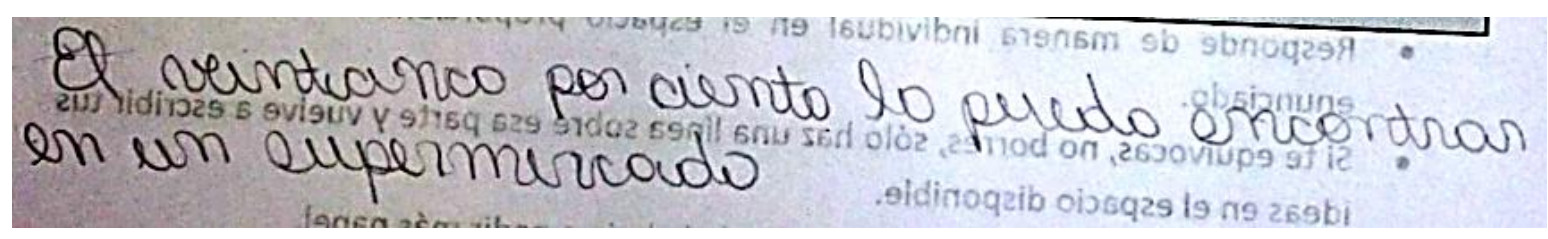

Figura 19. Respuesta de B7b08 a la pregunta 2

En los ejemplos se aprecia la combinación de numeral y palabras como una alternativa a la notación tradicional.

\section{d) Como una relación aritmética}

En las respuestas hemos detectado dos posibilidades de representación que utilizan relaciones aritméticas, ellas son: (a) relaciones aditivas que se refiere a diversas 
combinaciones aditivas en las que resulte 25 , valor al que pueden añadir o no el símbolo $\%$ y (b) relaciones multiplicativas y aditivo-multiplicativas que considera multiplicación de valores que resulten 25, o bien, la combinación de multiplicación y adiciones que den como resultado 25 . La tabla 22 presenta las frecuencias de este tipo de respuestas obtenidas.

Tabla 22. Variantes de respuestas de relaciones aritméticas

\begin{tabular}{lc}
\hline \multicolumn{1}{c}{ Tipo } & Frecuencia \\
\hline Aditivas & 10 \\
Aditivo-multiplicativas & 2 \\
Multiplicativas & 1 \\
Total & 13 \\
\hline
\end{tabular}

En la figura 20 se aprecia que las relaciones aritméticas son entre los números naturales y se buscan los cálculos de adición y multiplicación que resulten 25 , valor al que agregan el símbolo del porcentaje.

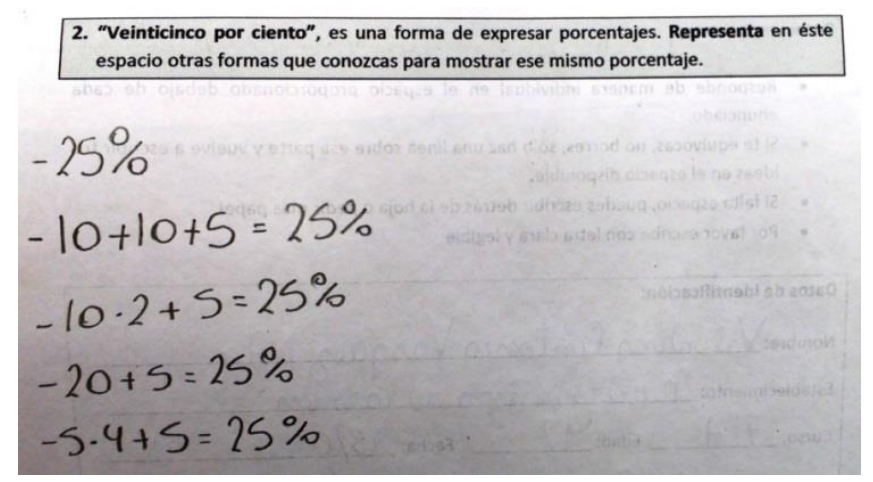

Figura 20. Respuesta de B7a17 a la pregunta 2

El estudiante busca distintas alternativas de relaciones aditivas o bien aditivas y multiplicativas que se ajusten al porcentaje solicitado.

\section{e) Otras representaciones}

En la tabla 23 se consideran formas que se presentan de modo singular como alternativa de representación del porcentaje. 
Tabla 23. Otros modos de representación

\begin{tabular}{lc}
\hline \multicolumn{1}{c}{ Tipo } & Frecuencia \\
\hline $25 * 100$ & 1 \\
$2 y 5 y \%$ & 1 \\
Escribe "en gráficos" & 1 \\
Total & 3 \\
\hline
\end{tabular}

La figura 21 ejemplifica la representación que considera de manera unitaria cada número y símbolo.

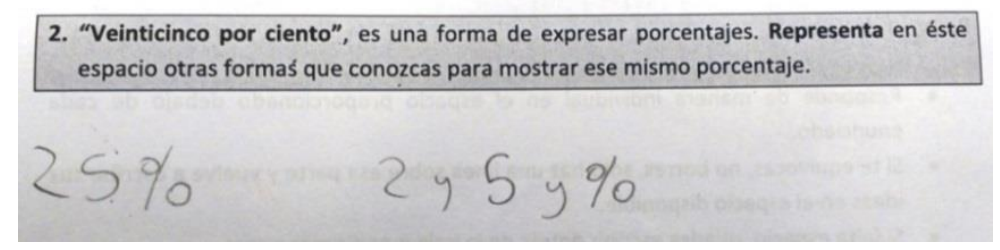

Figura 21. Respuesta de A7a17 a la pregunta 2

\subsubsection{Análisis a la pregunta 2 desde las componentes de la terna semántica}

En una segunda revisión de las respuestas, buscamos identificar indicios de las componentes "sentidos y modos de uso" y "estructura conceptual".

En relación con la componente del sentido, son predominantes los descuentos como situaciones propias de contextos comerciales. Se añaden aquellas situaciones personales como las de cocina, cuando expresan preferencias o bien, aspectos laborales como el aumento o disminución del sueldo. Notamos que cuando muestran un determinado porcentaje lo asocian al término "descuento", incluso utilizan abreviaturas que no son propias de un lenguaje matemático como se muestra en los ejemplos de la figura 22.
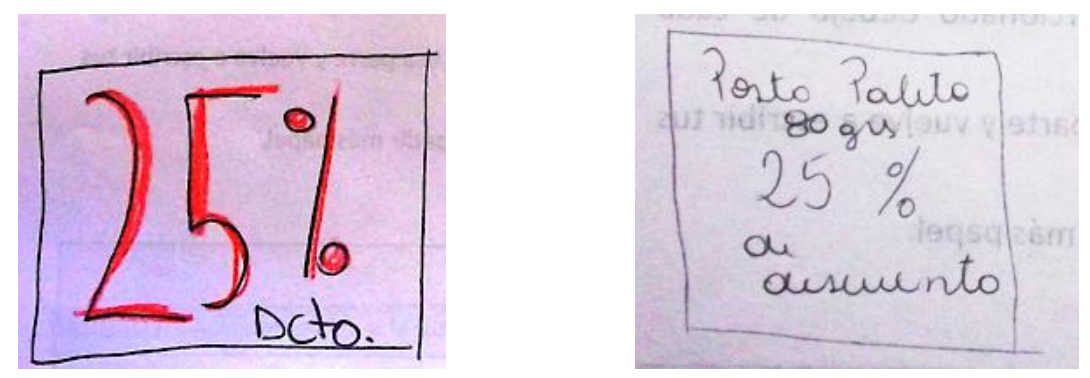

Figura 22. Respuesta de A7a09 y de B7a15 a la pregunta 2 
En términos de estructura, se identifica nuevamente la relación parte-todo aditiva y multiplicativa; un estudiante alude a operaciones aritméticas como formas de representar un determinado porcentaje, mientras que otro establece la equivalencia de algunos porcentajes con fracciones. Las figuras 23 y 24 son ejemplos de ello.

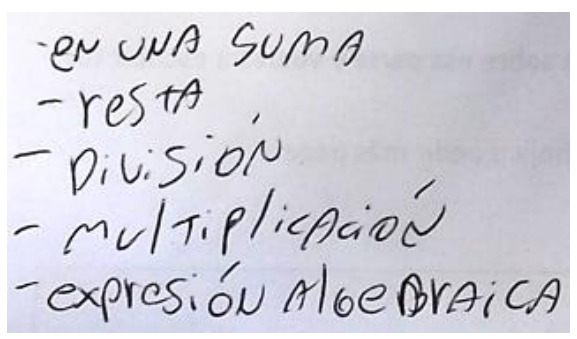

Figura 23. Respuesta de A7a07 a la pregunta 2

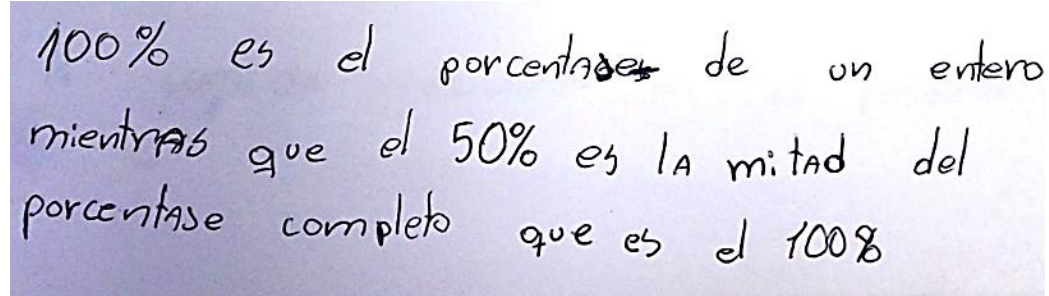

Figura 24. Respuesta de $\mathrm{C} 7 \mathrm{a} 24$ a la pregunta 2

\subsubsection{Síntesis de los resultados a la pregunta 2}

La tabla 24 muestra la síntesis de los diferentes sistemas de representación empleados por los estudiantes y su frecuencia, sin distinguir entre respuestas correctas e incorrectas.

Tabla 24. Síntesis de representaciones para el porcentaje

\begin{tabular}{lcc}
\hline \multicolumn{1}{c}{ Tipo de representación } & Frecuencia & $\%$ \\
\hline Numérico-simbólicas & 93 & 63 \\
Gráficas & 18 & 12 \\
Como una expresión aritmética & 13 & 9 \\
Verbales & 8 & 5 \\
Otras & 3 & 2 \\
No contesta & 12 & 8 \\
Total & 147 & 100 \\
\hline
\end{tabular}


Como se puede apreciar el sistema de representación más empleado del porcentaje es la notación numérico-simbólica convencional de un numeral seguido del símbolo \%.

Las representaciones gráficas se presentan con menor frecuencia, destacando los diagramas continuos de área, que reflejan una relación parte-todo, que se asocia a las formas gráficas de representar las fracciones. Destacan las situaciones de descuento de forma predominante y la relación parte-todo multiplicativa como estructura conceptual, que emerge de las respuestas obtenidas a esta segunda pregunta.

\subsection{Análisis de las respuestas a la pregunta 7}

El enunciado planteado en la séptima pregunta es "Explica con tus propias palabras en qué consiste un tanto por ciento". En la tabla 25, presentamos las variantes de respuestas que han dado los estudiantes, las cuales hemos agrupado en temas según su similitud.

Tabla 25. Frecuencia de respuestas distintas a la pregunta 7

\begin{tabular}{lc}
\hline \multicolumn{1}{c}{ Respuestas distintas a la pregunta 7 } & Frecuencia \\
\hline 1. En descontar del total & 26 \\
2. Representa una parte de un número, una cifra o algo & 8 \\
3. Restarle al precio & 5 \\
4. Sacar el porciento de algo & 3 \\
5. La mitad & 3 \\
6. Agregar o disminuir & 3 \\
7. Muestra una gráfica circular con una parte señalada & 2 \\
8. Algo rebajado, que se baja a un número & 2 \\
9. En dar un ejemplo sin dar a conocer el valor del número & 2 \\
10. En repartir algo, repartir en partes iguales & 2 \\
11. Porcentaje como representación de una cantidad & 2 \\
12. Lo que algo tiene demás & 2 \\
13. Depende de cómo se vea & 1 \\
14. La mitad de la mitad & 1 \\
15. En dar a conocer un porcentaje & 1 \\
16. Una probabilidad & 1 \\
17. Cualquier número con el símbolo “o” & 1 \\
18. Un porcentaje que se da... & 1 \\
19. Una cantidad de... & 1 \\
20. Un porcentaje sacado de un total & 1 \\
21. Ayuda a las personas por las posibilidades del mundo & 1 \\
&
\end{tabular}




\begin{tabular}{clc}
\hline & \multicolumn{1}{c}{ Respuestas distintas a la pregunta 7 } & Frecuencia \\
\hline 22. & Aumentar & 1 \\
23. & Un número que demuestra cantidad & 1 \\
24. & Una parte proporcional del entero & 1 \\
25. & Lo que sobra de algo & 1 \\
26. & Lo que se debe o falta & 1 \\
27. & El resultado de algo & 1 \\
28. Es el total de un valor & 1 \\
29. $\quad$ Porcentaje de precio u otra cosa & 1 \\
30. Mientras más grande el porcentaje, menos precio se paga & 1 \\
31. $\quad$ Que el total es el 100\% & 1 \\
32. Consiste en restar y a veces aumentar en la vida cotidiana & 1 \\
33. $\quad$ Cifra limitada que puede cambiar según la situación & 1 \\
Total & & 83 \\
\hline
\end{tabular}

El análisis de esta pregunta se ha realizado en base a la terna semántica de un concepto de las matemáticas escolares, es decir, se han revisado las respuesta buscando identificar si se manifiesta o no una estructura conceptual, unos sistemas de representación y unos sentidos y modos de uso.

La abstención de 37 participantes en esta pregunta, se podría corresponder a un mayor grado de complejidad. De las 63 respuestas, 21 alumnos utilizan sistemas de representación en sus planteamientos, identificándose hasta dos formas distintas por estudiante. La tabla 26 detalla los tipos de representaciones que hemos identificado junto a su frecuencia.

Tabla 26. Tipos de representaciones identificadas en la pregunta 7

\begin{tabular}{lc}
\hline \multicolumn{1}{c}{ Representación } & Frecuencia \\
\hline Notación de porcentaje $(x \%)$ & 10 \\
Aluden al porcentaje como una representación & 6 \\
Gráfica & 3 \\
Simbólica $(\%)$ & 3 \\
Verbal & 1 \\
Total & 23 \\
\hline
\end{tabular}


En la respuesta del alumno A7a27, "Consiste en cuanto por ciento es algo, por ejemplo: 50\% reemplaza que está a mitad de precio algo o está a un descuento", el estudiante utiliza la notación tradicional del porcentaje cuando quiere explicar con sus palabras en qué consiste.

En las figuras 25 y 26 se evidencia que los estudiantes tienen una noción del porcentaje que sólo se limita al uso de un símbolo. En estas respuestas, podemos inferir un significado parcial manifestado por estos estudiantes.

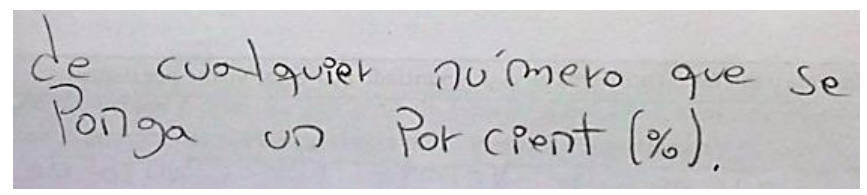

Figura 25. Respuesta de A7a17 a la pregunta 7

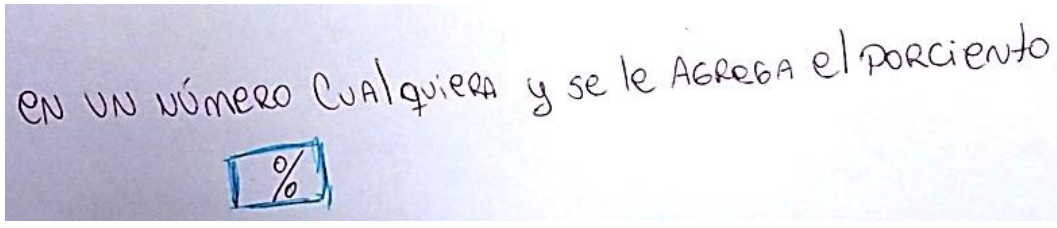

Figura 26. Respuesta de C7a36 a la pregunta 7

En el ejemplo de la figura 27, el estudiante usa una representación gráfica que complementa su explicación del porcentaje.

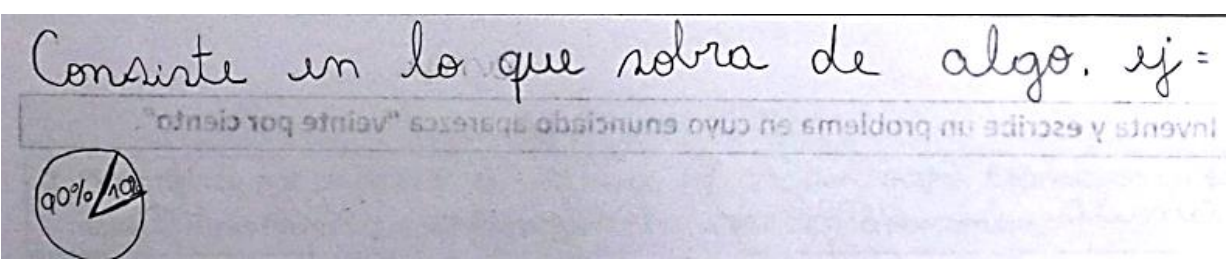

Figura 27. Respuesta de B7a08 a la pregunta 7

Con respecto a la componente sentido, hemos identificado sentidos y modos de uso vinculados con el porcentaje, los cuales se muestran en la tabla 27. Al igual que en las preguntas 1 y 2 , el contexto de descuento tiene una presencia predominante. 
Tabla 27. Tipos de sentidos y modos de uso identificados en la pregunta 7

\begin{tabular}{lc}
\hline \multicolumn{1}{c}{ Sentidos } & Frecuencia \\
\hline Comerciales (descuentos y deudas) & 32 \\
Situaciones de aumento y disminución & 5 \\
Como expresión de una cantidad & 3 \\
Situaciones de probabilidad & 2 \\
Situaciones de reparto & 1 \\
Como algo que sobra & 1 \\
Situaciones de problemas & 1 \\
Total & 45 \\
\hline
\end{tabular}

La asociación que los estudiantes hacen entre el porcentaje y la idea de descuento que se ha manifestado también en el análisis de las preguntas 1 y 2 la exponemos mediante los siguientes ejemplos de respuesta:

- "Consiste en descontar del total” (A7a05)

- "Consiste en cuanto por ciento es algo, por ejemplo: 50\% reemplaza que está a mitad de precio algo o está a un descuento" (A7a27)

Identificamos estudiantes que explican el porcentaje aludiendo al contexto de cambio o variaciones, sean de aumento o disminución respecto a una cantidad, es decir, porcentaje como expresión de un cambio de un valor, dentro de una estructura aditiva. Por ejemplo la respuesta del estudiante B7b11 "Un porciento nos ayuda para saber en cuanto se disminuye algo o cómo aumenta algo, ¿y por qué no se usan números? No se usan ya que el \% representa mejor lo que les dije anteriormente". Además, resalta la idea de entender el porcentaje como un modo de representar cantidades.

La respuesta "Un tanto por ciento es un número que demuestra cantidad", da cuenta de estudiantes que explican el tanto porciento como una forma de mostrar una medida, de expresión de cantidad, mientras que la figura 28, ejemplifica una manera de entender el porcentaje como probabilidad. 


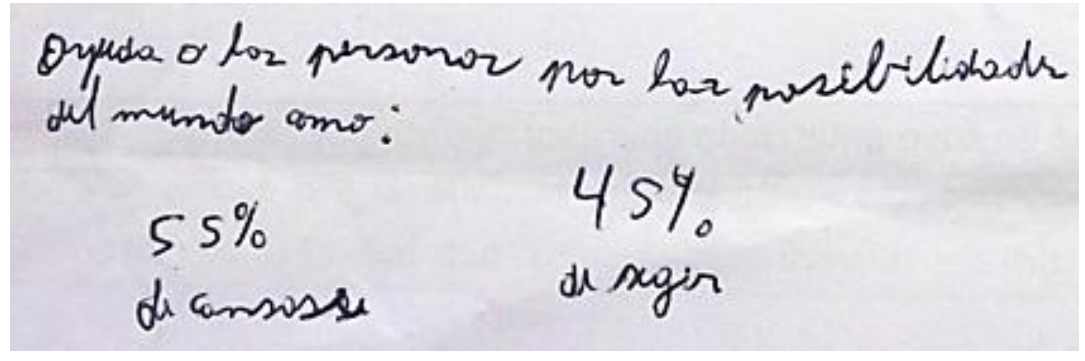

Figura 28. Respuesta de A7a25 a la pregunta 7

Las figuras 29 y 30 son ejemplo de los estudiantes que explican el porcentaje asociándolo a la idea de reparto o bien como expresión de algo sobrante respectivamente.

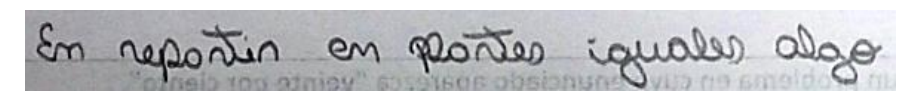

Figura 29. Respuesta de B7a07 a la pregunta 7

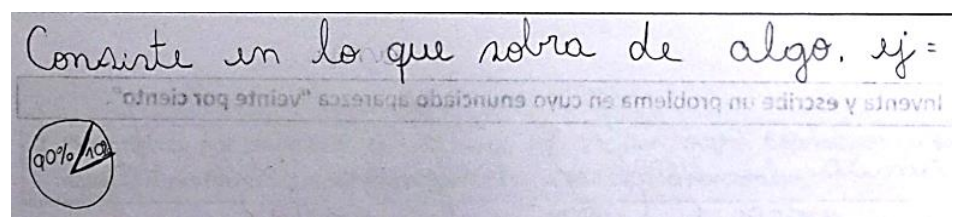

Figura 30. Respuesta de B7a08 a la pregunta 7

Resaltamos la respuesta "Lo que consiste es que: para representar descuentos, disminuciones de dinero, para representar productos que traen cierto extra y para muchas cosas más. Esto se utiliza mucho en la vida diaria" (B7a08). En ella se evidencia la riqueza de significados de la noción de porcentaje que puede manifestar un estudiante, ya que alude a varios sentidos vinculados a distintas referencias (descuento, disminución, cantidad extra) y a la representación.

Las respuestas que se han analizado van más allá de expresar un sentido o modo de uso, ya que incluyen aspectos conceptuales y estructurales tales como: operaciones aditivas y/o multiplicativas, cantidades relativas, repartos, medida, medida de la ocurrencia de un suceso (probabilidad). 
En cuanto a la componente de la estructura conceptual vinculada a la noción de porcentaje en la pregunta 7 , la tabla 28 presenta las relaciones matemáticas que manifiesta el alumnado a través de sus respuestas.

Tabla 28. Elementos de la estructura conceptual identificados en la pregunta 7

\begin{tabular}{lc}
\hline \multicolumn{1}{c}{ Relaciones } & Frecuencia \\
\hline Disminución (cambio aditivo) & 32 \\
Relación parte-todo aditiva & 10 \\
Parte-todo multiplicativa & 4 \\
Operador & 4 \\
Resultado de la medida & 3 \\
Comparación & 2 \\
Medida de un suceso (probabilidad) & 2 \\
Aumento (cambio) & 2 \\
Relación inversa & 1 \\
Proporcionalidad & 1 \\
Otros (redundantes) & 4 \\
Total & 65 \\
\hline
\end{tabular}

Resalta la frecuencia obtenida por las relaciones de cambio (estructura aditiva), principalmente las de disminución, asociadas al descuento, término clave que también se manifiesta fuertemente en el análisis de esta pregunta que pedía explicar en qué consiste un tanto por ciento. Ejemplos de ello son las respuestas de los estudiantes A7a05 "consiste en descontar del total", A7a14 "que se baja un número o algo rebajado", A7a32 "la o el porciento significa como el descuento del total de algo", B7a02 que se muestra en la figura 31.

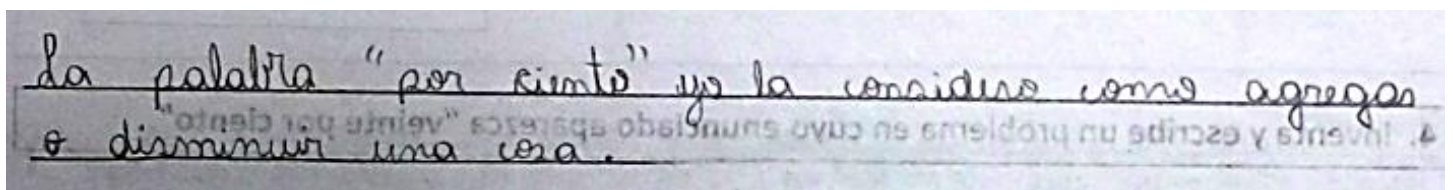

Figura 31. Respuesta de B7a02 a la pregunta 7

Las respuestas "Un porciento es una parte de un número como el 2,3\% de 2" (alumno A7a13) y "El porciento es una parte de algo como 25\% de 100" (alumno B7a06) dan cuenta de indicios que aluden a la relación parte-todo en las respuestas de los estudiantes. 
Indicadores de la estructura multiplicativa se ejemplifican en la respuesta del alumno A7a12, "Puede ser un tanto por ciento de descuento o más, se describe la mitad y la mitad de la mitad". En ella, el estudiante explica el tanto por ciento mediante una situación de uso.

La respuesta del estudiante B7a05, "Un porcentaje o tanto por ciento consiste en una parte proporcional de un entero, es decir una parte del entero que es representada con exactitud como un porcentaje", muestra una explicación en que resalta la idea de una relación proporcional, de tipo multiplicativo.

En la figura 32, identificamos un estudiante que explica el porcentaje mediante una relación proporcional inversa, en su respuesta utiliza además representaciones que complementan su explicación y dan cuenta de la riqueza de significado que ha asimilado. También alude a un modo de uso en las rebajas.

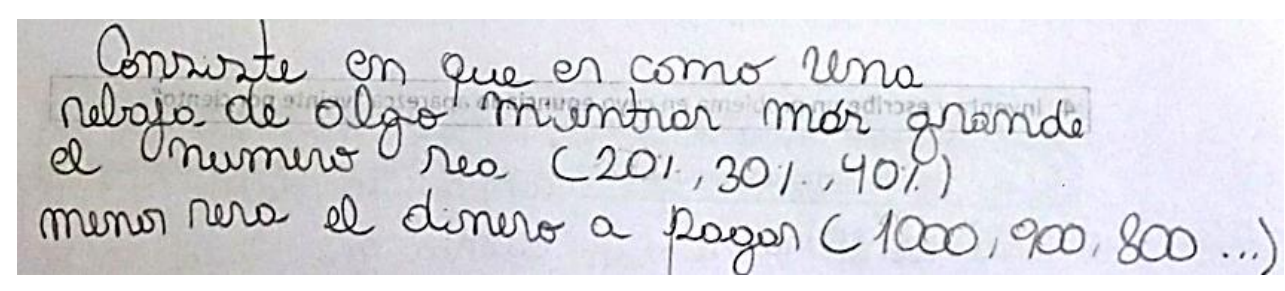

Figura 32. Respuesta de B7b07 a la pregunta 7

Ejemplos de interpretación del porcentaje como operador lo encontramos en las respuestas "Es el total de un valor" (B7b07) y "Un tanto por ciento puede ser el descuento que le dan a algo o el resultado de algo" (B7a14). Inferimos que con la idea de total o resultado, estos estudiantes se refieren al efecto de transformar unos valores en otros mediante la aplicación de un determinado porcentaje.

\subsection{Componentes del significado en las preguntas 1, 2 y 7}

A continuación nos centramos en identificar los componentes del significado presentes conjuntamente en las respuestas proporcionadas por los estudiantes a las preguntas 1, 2 y 7 del cuestionario. Con ello, buscamos evidenciar como estos tres organizadores del significado se manifiestan de forma natural en las ideas expresadas por el alumnado, aunque las preguntas se diseñaron con un foco específico. 
La tabla 29 muestra la presencia o ausencia de los sistemas de representación en las respuestas que los estudiantes dieron a las preguntas 1, 2 y 7 considerando los 100 estudiantes que conforman la muestra de este estudio, por ende se puede realizar la interpretación porcentual de la frecuencia.

Tabla 29. Representaciones en las preguntas 1, 2 y 7

\begin{tabular}{lc}
\hline Presencia de representaciones & Frecuencia \\
\hline En las 3 preguntas & 14 \\
En 2 de las preguntas & 32 \\
En 1 de las preguntas & 48 \\
No aparecen & 6 \\
Total & 100 \\
\hline
\end{tabular}

En cuanto al sentido y modos de uso, en la tabla 30, se muestra la frecuencia de estudiantes que reconoce al menos un sentido para el concepto de porcentaje.

Tabla 30. Sentidos y modos de uso en las preguntas 1, 2 y 7

\begin{tabular}{lc}
\hline Presencia de sentidos & Frecuencia \\
\hline En las 3 preguntas & 8 \\
En 2 de las preguntas & 35 \\
En 1 de las preguntas & 43 \\
No aparecen & 14 \\
Total & 100 \\
\hline
\end{tabular}

La tabla 31 da cuenta de los estudiantes que aportan indicios de la estructura conceptual en sus respuestas.

Tabla 31. Estructura conceptual en las preguntas 1, 2 y 7

\begin{tabular}{lc}
\hline Elementos de la estructura conceptual & Frecuencia \\
\hline En las 3 preguntas & 0 \\
En 2 de las preguntas & 2 \\
En 1 de las preguntas & 35 \\
No aparecen & 63 \\
Total & 100 \\
\hline
\end{tabular}


Como se puede apreciar, la estructura conceptual es la componente de significado cuyos elementos tienen menor presencia en las respuestas de los estudiantes a estas preguntas.

\subsection{Síntesis de resultados del análisis a las preguntas 1,2 y 7}

Al considerar la totalidad de la muestra del estudio (100 participantes), encontramos que 94 estudiantes utiliza algún tipo de representación asociada a la noción de porcentaje, 86 aluden al menos a un sentido o posible modo de uso y sólo 37 de ellos expresan indicios acerca de una estructura conceptual.

El sistema de representación empleado mayoritariamente corresponde a la representación numérico-simbólica tradicional del porcentaje. Dentro del escaso número de estudiantes que dan cuenta de una estructura conceptual que sustente la noción de porcentaje, se presenta la relación parte-todo aditiva con mayor frecuencia y, por último, las situaciones laborales de tipo comercial, junto con el término "descuento", identifican el sentido de porcentaje con mayor presencia para estos alumnos.

Como se puede apreciar, la componente "representaciones" del significado proporciona elementos necesarios para referirse a un determinado concepto; la componente "sentido" da razón de ser del concepto desde los distintos modos de uso con que se puede interpretar y emplear; finalmente la componente "estructura conceptual", constituye el soporte matemático desde el cual un determinado enunciado relativo a ese concepto o noción se puede considerar como verdadero o falso. Esto se aprecia en el hecho de que las tres componentes del significado de un concepto de las matemáticas escolares son parte natural de los modos en que los estudiantes se expresan en torno al concepto de porcentaje, y seguramente de otros conceptos o nociones.

Finalmente, los sistemas de representación, la estructura conceptual y los sentidos y modos de uso están presentes, de manera explícita o implícita, en los significados parciales que internalizan los escolares, tanto desde sus experiencias educativas como cotidianas. 


\section{CAPÍTULO 5: CONCLUSIONES DEL ESTUDIO}

En este capítulo se recogen las conclusiones extraídas a partir del análisis del contenido de las respuestas de los escolares mediante las categorías de significado consideradas, se revisa el logro de los objetivos planteados, se señalan las limitaciones de la investigación y se exponen sugerencias de continuidad para estudios posteriores.

\subsection{Conclusiones generales en función de los objetivos planteados}

Al iniciar el estudio, nos planteamos el objetivo general de indagar y describir los significados del concepto de porcentaje internalizados por los estudiantes tras un primer acercamiento escolar a esta noción. Para llevarlo a cabo, se propusieron cuatro objetivos específicos, que se rememoran a continuación, junto con una breve descripción de los resultados obtenidos.

El primer objetivo establecido fue "Construir un cuestionario semántico que recoja indicios de las expresiones y las representaciones mediante las cuales los estudiantes se expresan sobre el concepto de porcentaje". Consideramos que se logró este objetivo, ya que elaboramos un cuestionario semántico, de respuesta abierta, respetando criterios de fiabilidad y de validez, el cual ha permitido recoger una gran cantidad de información factible de analizar desde la terna semántica representación-estructura conceptual-sentido.

El segundo objetivo plateado fue "Identificar y categorizar los sentidos y modos de uso empleados por los estudiantes al expresar sus ideas acerca del porcentaje". Tras la identificación de elementos relativos a las categorías del sentido de un concepto matemático escolar -términos, situaciones, fenómenos y contexto- clasificamos esas respuestas según dichos elementos, previamente establecidos. El análisis mostró el predominio de las situaciones laborales del ámbito comercial, siendo "descuento" un término que los estudiantes vinculan directamente con la noción de porcentaje y que se manifestó con mayor frecuencia en las tres preguntas analizadas, junto con otras variantes como ofertas y rebajas. Se identificaron respuestas que se ajustan a contextos de cambio 
donde el porcentaje indica aumento o disminución respecto a una cantidad determinada y por último, la identificación de situaciones del ámbito comercial permite rememorar los fenómenos mercantiles en los cuales la noción de porcentaje tuvo sus orígenes.

Nuestro tercer objetivo fue "Identificar y describir los modos de representación que emplean los estudiantes para referirse al porcentaje". En las respuestas recogidas, logramos identificar representaciones gráficas (diagramas continuos de área y gráficas estadísticas), expresiones verbales, numérico-simbólicas junto con algunas relaciones parte-todo que se ajustan a una estructura aritmética aditiva o multiplicativa, o bien a una combinación de ambas. El sistema de representación más empleado fue la notación numérico-simbólica tradicional que consta de un numeral seguido del símbolo \%.

Por último, el cuarto objetivo específico fue "Interpretar y describir los conceptos, relaciones y propiedades puestos de manifiesto por los estudiantes al referirse a la noción de porcentaje". Tras el análisis de las respuestas, encontramos que la estructura conceptual en que se enmarca el concepto sólo es puesta en evidencia por una minoría del alumnado. La relación parte-todo aflora de manera natural en las respuestas obtenidas, principalmente la aditiva. También identificamos respuestas que dan cuenta de relaciones proporcionales, relaciones inversas, porcentaje como resultado de la medida y la consideración del porcentaje como un operador que se presentan con menor frecuencia.

\subsection{Aportaciones del estudio}

De este estudio es posible extraer aportaciones respecto a la noción de porcentaje, orientadas al tratamiento de su contenido, de su aprendizaje y de su evaluación.

Desde un planteamiento curricular del contenido, contribuimos a identificar variables que pueden incidir en el tratamiento dado a la noción de porcentaje en las matemáticas escolares, las que hemos puesto de manifiesto con los términos asociados, los sentidos y modos de uso, las representaciones y aspectos estructurales que asimilan los estudiantes tras un primer acercamiento escolar a la noción del porcentaje. 
El análisis del significado realizado en el marco teórico, aporta un panorama general de las componentes del significado del concepto de porcentaje factible de considerar al diseñar tareas y situaciones de aprendizaje que aborden de manera más completa el tratamiento escolar de esta noción.

En cuanto al aprendizaje, este estudio permite detectar los significados parciales internalizados por el alumnado que han manifestado en sus respuestas al cuestionario semántico. Al tomar conciencia de la interpretación incompleta del concepto, queda la responsabilidad de tomar decisiones en la planificación de la enseñanza y en el diseño de tareas que puedan mejorar esa interpretación parcial de la noción en cuestión y por ende mejorar los aprendizajes.

Mediante este estudio diferenciamos entre la evaluación realizada al finalizar una unidad didáctica, de la evaluación de su comprensión, puesto que, mediante el cuestionario semántico, recogemos y analizamos el significado como aquello que permanece sobre un concepto, más allá de su definición formal.

Finalmente, consideramos que con este estudio aportamos evidencia empírica de la pertinencia de las componentes de significado como sistema de clasificación, análisis e interpretación de las respuestas proporcionadas por los estudiantes mediante el cuestionario semántico, ya que hemos detectado que las representaciones, los sentidos o modos de uso y la estructura conceptual subyacen en las expresiones del alumnado en torno al porcentaje.

\subsection{Limitaciones de la investigación}

El trabajo que aquí se presenta tiene las limitaciones de un estudio exploratorio e interpretativo, con muestra reducida de escolares, propio de las investigaciones educativas de iniciación.

Una de las limitaciones asumida ha sido la elección de la muestra, seleccionada de manera intencional y por disponibilidad. Si bien hemos respetado criterios generales de representatividad, es obvio que no se trata de un estudio experimental ni cuasi 
experimental. Los resultados muestran evidencia de la ocurrencia de determinados hechos, que, en este trabajo exploratorio e interpretativo, no se proponen su generalización.

También ha sido una limitante el poco tiempo disponible para el estudio de todo el cuestionario, debiendo acotar el análisis a las tres preguntas que se presentan en esta memoria, lo cual ha producido que algunas categorías de análisis queden vacías y sin interpretación hasta ahora, sin embargo, con el análisis de las demás preguntas del cuestionario se pueden hacer operativas.

\subsection{Líneas abiertas}

La principal línea abierta que deja este trabajo de investigación, es avanzar y profundizar con el análisis de las respuestas obtenidas a las preguntas del cuestionario semántico aplicado, con el fin de ampliar el estudio del significado sobre el concepto de porcentaje.

Consideramos relevante profundizar en la interpretación de conceptos matemáticos escolares destacando que, aunque parezcan sencillos como la noción de porcentaje, tienen gran riqueza de significados, la cual se refleja en sus variados modos de representación, sus sentidos o modos de uso y las estructuras conceptuales que los sustentan, y que son expresados de manera parcial por el alumnado, evidenciando la asimilación de significados parciales e incompletos.

Este estudio del significado de un concepto de la matemática escolar es factible de realizar también a nivel del profesorado, en ejercicio o en formación, para contrastar con los resultados del alumnado. Ello, podría motivar la búsqueda de alternativas de formación que contribuyan a ampliar la comprensión de los conceptos matemáticos tanto de los profesores como de los estudiantes. 


\section{REFERENCIAS}

Alexándrova, N. V. (Ed.) (2015). Diccionario histórico de notaciones, términos y conceptos de las matemáticas (Navarro, C. D., Palomino, J. E. y Abanto, Y., Trad.). Moscú, Rusia: URSS.

Arnau, H., Bastons, C, Domènech, M., López-Jordà, F., López Solanas, V., Ruiz, F., Sariol, J. (1997). Diccionario terminológico (1ºd.). Barcelona, España: Vicens Vives.

Cajori, F. (1993). A history of mathematical notations. New York, NY: Dover.

Castro, E. y Castro, E. (1997). Representaciones y modelización. En L. Rico (Ed.), La Educación Matemática en la enseñanza secundaria (pp. 95-124). Barcelona, España: Horsori.

Chávez, C. y León. A. (2001). La biblia de las matemáticas. Cali, Colombia: Imprelibros.

Cockcroft, W. H. (1985). Las Matemáticas sí cuentan. Informe Cockroft. Madrid, España: MEC.

Dirección de Currículum. (1994). Actualización curricular E. G. B. primer ciclo. Matemática. Documento de trabajo $N^{o}$ 2. Buenos Aires, Argentina: Autor.

Fernández-Plaza, J. A., Castro-Rodríguez, E., Estrella, M., Martín-Fernández, E., Rico, L., Ruiz-Hidalgo, J. F. y Vílchez-Marín, M. (en prensa). Significado y concepciones de conceptos matemáticos escolares. En Investigación en Educación Matemática XX. Málaga, España: SEIEM.

Fernández, F. y Segovia, I. (2011). Proporcionalidad entre magnitudes. Medidas indirectas. En I. Segovia y L. Rico (Eds.), Matemáticas para maestros de educación primaria (pp. 375-400). Madrid, España: Pirámide.

Frege, G. (1998). Ensayos de semántica y filosofía de la lógica (Valdés, L. M., Trad.). Madrid, España: Tecnos.

Gairín, J. y Sancho, J. (2002). Números y algoritmos. Madrid, España: Síntesis.

García, P. (1992). Diccionario de términos matemáticos. Valladolid, España: La Calesa.

Hernández, R., Fernández, C. y Baptista, P. (2007). Fundamentos de metodología de la investigación (4º ed.). Madrid, España: McGraw-Hill.

Johnson, B. y Christensen, L. (2014). Educational research: Quantitative, qualitative, and mixed approaches $\left(5^{\circ}\right.$ ed.). Thousand Oaks, CA: Sage. 
Lee, C. S. (2010). El lenguaje en el aprendizaje de las matemáticas: la evaluación formativa en la práctica. Madrid, España: Morata.

Lee, K. P. (1998). The knowledge of percent of pre-service teachers. The Mathematics Educator, 3(2), 54-69.

Lupiáñez, J. L. (2013). Análisis didáctico: la planificación del aprendizaje desde una perspectiva curricular. En L. Rico, J. L. Lupiáñez y M. Molina (Eds.), Análisis didáctico en Educación Matemática: metodología de investigación, formación de profesores e innovación curricular (pp. 81-101). Granada, España: Comares.

Maz-Machado, A. y Gutiérrez, M. P. (2008). Errores de los estudiantes de magisterio frente a situaciones que implican porcentajes. Enseñanza de la Matemática, 17(1), 59-69.

Maza, C. (2000). Análisis de la formulación y resolución de problemas porcentuales de cambio en estudiantes para maestro (Tesis doctoral no publicada). Universidad de Sevilla, España.

Mendoza, T. (2007). Estudio didáctico de la noción de porcentaje (Tesis de maestría no publicada). CINVESTAV-IPN, México.

Mendoza, T. (2009, Septiembre). La noción de porcentaje: procedimientos, errores e interpretaciones de estudiantes de secundaria. Ponencia presentada en el $\mathrm{X}$ Congreso Nacional de Investigación Educativa. Área 5: educación y conocimientos disciplinares. Recuperado a partir de http://www.comie.org.mx/congreso/memoriaelectronica/v10/pdf/area_tematica_05/ ponencias/0300-F.pdf

Mendoza, T. y Block, D. (2010). El porcentaje: lugar de encuentro de las razones, fracciones y decimales en las matemáticas escolares. RELIME, 13(4), 177-190.

Mineduc. (2012). Matemática educación básica. Bases curriculares. Santiago, Chile: Autor.

Mineduc. (2013). Matemática. Programa de estudio sexto año básico. Santiago, Chile: Unidad de Currículum y Evaluación.

Ministerio de Educación, Cultura y Deporte. (2014). Real Decreto 126/2014, de 28 de febrero, por el que se establece el currículo básico de la educación primaria. $B O E$, (52), 19349-19420.

Moliner, M. (2007). Diccionario de uso del español (3ºd.). Madrid, España: Gredos.

Moliner, M. (2013). Diccionario de sinónimos y antónimos (2ºd). Madrid, España: Gredos. 
NCTM. (2000). Principios y estándares para la educación matemática (SAEM Thales Trans.). Sevilla, España: SAEM Thales.

OCDE. (2005). Informe PISA 2003. Aprender para el mundo del mañana (Rodríguez, M. L., Gordo, V. y García, J. Trad.). Madrid, España: Santillana.

Parker, M. y Leinhardt, G. (1995). Percent: A privileged proportion. Review of Educational Research, 65(4), 421-481.

Pimm, D. (2000). El lenguaje matemático en el aula. Madrid, España: Morata.

Real Academia Española y Asociación de Academias de la Lengua Española (Eds.). (2005). Diccionario panhispánico de dudas. Madrid, España: Autor.

Real Academia Española. (2014). Diccionario de la lengua española (23 ed.). Madrid, España: Autor.

Rico, L. (2009). Sobre las nociones de representación y comprensión en la investigación en educación matemática. PNA, 4(1), 1-14.

Rico, L. y Díez-Lozano. Á. (2011). Las matemáticas y el maestro de primaria. En I. Segovia y L. Rico (Eds.), Matemáticas para maestros de educación primaria (pp. 23-46). Madrid, España: Pirámide.

Rico, L. y Fernández-Cano, A. (2013). Análisis didáctico y metodología de investigación. En L. Rico, J. L. Lupiáñez Gómez y M. Molina (Eds.), Análisis didáctico en educación matemática: metodología de investigación, formación de profesores e innovación curricular (pp. 1-22). Granada, España: Comares.

Rico, L. y Lupiáñez, J. L. (2008). Competencias matematicas desde una perspectiva curricular. Madrid, España: Alianza.

Rico, L., Flores, P. y Ruiz-Hidalgo, J. F. (2015). Enseñanza de las matemáticas con sentido. $U N O,(70), 48-54$.

Ruiz-Hidalgo, J.F. y Fernández-Plaza, J.A. (2013). Planificación de unidades didácticas en enseñanza secundaria mediante el uso del análisis didáctico. En L. Rico, J. L. Lupiáñez Gómez y M. Molina (Eds.), Análisis didáctico en educación matemática: metodología de investigación, formación de profesores e innovación curricular (pp. 1-22). Granada, España: Comares.

Segura, S. (Ed.). (2010). Libro de los números: los números en la formación del léxico. Bilbao, España: Universidad de Deusto.

Smith, D. E. (1958). History of mathematics. New York, NY: Dover. 
Valverde, G. (2013). Competencias matemáticas promovidas desde la razón y la proporcionalidad en la formación inicial de maestros de educación primaria (Tesis doctoral no publicada). Universidad de Granada, España.

Vidaurrí, H. M. (2012). Matemáticas financieras (5ºd.). D. F., México: Cengage Learning.

Zurbano, E. (2002). Los porcentajes y su interpretación. En C. Penalva, G. Torregrosa y J. Valls (Eds.), Aportaciones de la didáctica de la matemática a diferentes perfiles profesionales (pp. 265-276). España: Universidad de Alicante. 
ANEXOS 


\section{Anexo A: Antecedentes históricos del porcentaje y de su notación}

El link que se adjunta, presenta la revisión histórica realizada en torno al concepto de porcentaje y de su notación.

Link de acceso:

https://drive.google.com/open?id=0B5ZGNYyRr0NAM2xhUzQtbkJuMHM 


\section{Anexo B: Normas de escritura de porcentajes}

El link que se adjunta a continuación, presenta las normas de escritura correctas del porcentaje señaladas por la Real Academia Española

Link de acceso:

https://drive.google.com/open?id=0B5ZGNYyRr0NAY1NBNWpKdmJ4ZFk 


\section{Anexo C: Descripción de los centros participantes del estudio}

El link adjunto a continuación, presenta una breve descripción de aspectos organizativos y socioeconómicos de los centros educativos que participan de este estudio.

Link de acceso:

https://drive.google.com/open?id=0B5ZGNYyRr0NAS2Y0YUVObDltRGM 


\section{Anexo D: Descripción de las fases de elaboración del cuestionario}

El link que se presenta a continuación, muestra la descripción detallada de cada una de las fases de elaboración del cuestionario semántico utilizado como instrumento de recogida de datos en este estudio.

Link de acceso:

https://drive.google.com/open?id=0B5ZGNYyRr0NAVXVuZmpqZIRVSnM 


\section{Anexo E: Cuestionario semántico}

El link adjunto a continuación, presenta el Cuestionario semántico, que ha sido especialmente diseñado para recoger información acerca de las concepciones de los estudiantes en torno al concepto de porcentaje.

Link de acceso:

https://drive.google.com/open?id=0B5ZGNYyRr0NAejQwMThHaFBDODQ 


\section{Anexo F: Carta solicitud de permiso}

El link que se presenta a continuación, muestra la carta enviada a los centros educativos, mediante la cual se solicitó el permiso correspondiente para aplicar el cuestionario semántico.

Link de acceso:

https://drive.google.com/open?id=0B5ZGNYyRr0NATFlqamRpUlV0V0k 


\section{Anexo G: Protocolo de aplicación del cuestionario}

El link que se presenta a continuación, muestra el protocolo de aplicación del cuestionario especialmente diseñado para orientar a los colaboradores que ejercieron el rol de encuestadores al momento de implementar el cuestionario semántico.

Link de acceso:

https://drive.google.com/open?id=0B5ZGNYyRr0NANUVlQ0NRVnVGQjg 


\section{Anexo H: Respuestas recogidas a la pregunta 1}

El link adjunto, presenta las respuestas que los participantes del estudio dieron a la primera pregunta del cuestionario.

Link de acceso:

https://drive.google.com/open?id=0B5ZGNYyRr0NAOFJ0Rk5vbU96Snc 


\section{Anexo I: Respuestas recogidas a la pregunta 2}

El link que se adjunta a continuación, presenta las respuestas que los participantes del estudio dieron a la segunda pregunta del cuestionario.

Link de acceso:

https://drive.google.com/open?id=0B5ZGNYyRr0NAQVpDdG1FUmNZZ2s 


\section{Anexo J: Respuestas recogidas a la pregunta 7}

El link adjunto, presenta las respuestas que los participantes del estudio dieron a la séptima pregunta del cuestionario.

Link de acceso:

https://drive.google.com/open?id=0B5ZGNYyRr0NASnFycWhVNGFzV3c 